OPEN ACCESS

Edited by:

Federica Galli,

Sapienza University of Rome, Italy

Reviewed by: Armando D'Agostino,

University of Milan, Italy

Fushun Wang,

Nanjing University of Chinese

Medicine, China

*Correspondence:

Ravi Philip Rajkumar ravi.psych@gmail.com

Specialty section: This article was submitted to Psychology for Clinical Settings, a section of the journal

Frontiers in Psychology

Received: 27 October 2020 Accepted: 22 February 2021

Published: 18 March 2021

Citation:

Rajkumar RP (2021) Harnessing the Neurobiology of Resilience to Protect the Mental Well-Being of Healthcare

Workers During the COVID-19

Pandemic.

Front. Psychol. 12:621853.

doi: 10.3389/fpsyg.2021.621853

\section{Harnessing the Neurobiology of Resilience to Protect the Mental Well-Being of Healthcare Workers During the COVID-19 Pandemic}

\author{
Ravi Philip Rajkumar*
}

Department of Psychiatry, Jawaharlal Institute of Postgraduate Medical Education and Research, Pondicherry, India

Healthcare workers are at a high risk of psychological morbidity in the face of the COVID-19 pandemic. However, there is significant variability in the impact of this crisis on individual healthcare workers, which can be best explained through an appreciation of the construct of resilience. Broadly speaking, resilience refers to the ability to successfully adapt to stressful or traumatic events, and thus plays a key role in determining mental health outcomes following exposure to such events. A proper understanding of resilience is vital in enabling a shift from a reactive to a proactive approach for protecting and promoting the mental well-being of healthcare workers. Research in the past decade has identified six areas that provide promising leads in understanding the biological basis of individual variations in resilience. These are: (1) the key role played by the monoamines noradrenaline and serotonin, (2) the centrality of the hypothalamic-pituitary-adrenal axis in influencing stress vulnerability and resilience, (3) the intimate links between the immune system and stress sensitivity, (4) the role of epigenetic modulation of gene expression in influencing the stress response, (5) the role played by certain neuropeptides as a natural "brake" mechanism in the face of stress, and (6) the neurobiological mechanisms by which environmental factors, such as exercise, diet, and social support, influence resilience to subsequent life events. Though much of this research is still in its early stages, it has already provided valuable information on which strategies - including dietary changes, lifestyle modification, environmental modification, psychosocial interventions, and even pharmacological treatments - may prove to be useful in fostering resilience in individuals and groups. This paper examines the above evidence more closely, with a specific focus on the challenges faced by healthcare workers during the COVID-19 pandemic, and provides suggestions regarding how it may be translated into real-world interventions, as well as how the more tentative hypotheses advanced in this field may be tested during this critical period.

Keywords: resilience, stress, neurobiology, neuroendocrinology, neuropeptides, cortisol, coronavirus disease 2019, epigenetics 


\section{INTRODUCTION}

\section{A Cautionary Tale}

The COVID-19 pandemic has taken a significant toll on the psychological well-being of healthcare workers, and that this impact remains substantial even in those who are not directly involved in caring for patients with this disease (da Silva and Neto, 2020). Based on experience from earlier outbreaks of similar severity and smaller scope (Maunder et al., 2008; Lee et al., 2018), this phenomenon was predicted well in advance, and in many cases, plans and services were developed to minimize the traumatic impact of COVID-19 on healthcare workers as the pandemic began to evolve and take on a truly global scope. One of the earliest reports of such an attempt, published in February, came from the Second Xiangya Hospital of Central South University, China, which was at the center of the initial COVID-19 outbreak (Chen et al., 2020a). The importance of this report, despite its anecdotal nature, was that it highlighted the limitations of the "conventional" approach to such problems. At this hospital, which was handling a large number of COVID-19 cases, a three-pronged approach was devised by a team of experts, which consisted of (i) a psychological intervention team which provided online courses to address common mental health problems, (ii) a dedicated hotline, and (iii) group psychological activities to minimize stress. Such an approach was in line with recommendations from the existing literature. However, the majority of staff were unwilling to participate in these activities, and many of them refused assistance from the team despite showing obvious signs of distress.

Interviews with the staff revealed that this program did not address their real-world concerns, which included separation from their families, difficulties in handling the anxieties of patients, worries regarding shortages of food, protective equipment, and other essential supplies, and a lack of time for sleep or leisure. This feedback led to an overhaul of the entire program, which now included (i) ensuring the availability of food and essential supplies, (ii) training staff to handle patients' concerns, (iii) provision of a rest area and leisure activities, and (iv) periodic visits by a counselor; on the other hand, there was a reduced emphasis on the exclusively psychological or counseling-based interventions which formed part of the initial plan. This approach led to greater satisfaction and a reduction in perceived stress among nursing and other staff.

What can we learn from the initial failure and later success of such programs? At a surface level, they highlight the need to listen to healthcare workers' actual concerns when designing interventions to improve their psychological well-being. However, a deeper insight into such occurrences can be obtained by a careful study of contemporary research into resilience, the multiple and interconnected biological mechanisms that underlie it, and the way in which resilience can be fostered by methods such as exercise, socialization, and environmental modification. The purpose of this paper is to provide an overview of this research, with a particular focus on how it might apply to the psychological health of healthcare workers in the context of the COVID-19 pandemic, and outline suggestions for how this knowledge can be translated into effective strategies for the prevention and management of psychological distress in this population.

\section{Reactive and Proactive Approaches to Psychological Health in Healthcare Workers During the COVID-19 Pandemic}

In a meta-analytic review of 13 observational studies, Pappa et al. (2020) have estimated that $23.2 \%$ of healthcare workers experience significant symptoms of anxiety in the context of the COVID-19 pandemic; $22.8 \%$ report significant depressive symptoms; and $38.9 \%$ screen positive for insomnia. Similar results were obtained in a meta-analysis of eight studies dealing exclusively with frontline healthcare workers (da Silva and Neto, 2020). Many of these observational studies have concluded with recommendations for the monitoring and treatment of healthcare workers with such symptoms (Huang and Zhao, 2020; Zhang et al., 2020b); however, only one paper pointed out the potential benefits of a preventive approach (Li et al., 2020). While it is essential that healthcare workers with emergent symptoms of psychological distress are identified and treated early, there are advantages to supplementing this conventional model with an approach based on enhancing the abilities of asymptomatic healthcare workers to cope with stress - in other words, with a resilience-based approach. Such a proactive approach will continue to gain importance as the COVID-19 pandemic continues to evolve, and even after it begins to abate, as large numbers of healthcare workers will remain exposed to stress, socioeconomic difficulties and ethical challenges over a prolonged period of time (Vinkers et al., 2020). The advantages of a proactive approach informed by an understanding of resilience include not only the prevention and mitigation of psychological distress, but improved functioning and an enhanced capacity to handle challenging or unpredictable situations in patient care, particularly in the setting of a scarcity of resources (Rosen et al., 2020; Vinkers et al., 2020). In addition, if successful, such an approach would reduce the burden faced by conventional mental health care services, and permit them to provide optimal care to those healthcare workers with more severe symptoms and greater treatment needs (Freeman, 2020).

\section{Understanding Resilience: Psychological and Neuroscience-Based Approaches}

Resilience can be defined as "the ability to adapt successfully in the face of stress and adversity" (Wu et al., 2013). In other words, it refers to the capacity to maintain a normal or nearnormal level of functioning, even when exposed to a stressful or traumatic event. It is a common-sense observation that, even after exposure to a traumatic event such as a natural or man-made disaster, not all individuals develop symptoms of psychological distress. Moreover, those who do so exhibit varying levels of such symptoms, with severe sequelae being the exception rather than the rule (Rutter, 2012). Resilience is best understood as a continuous, dynamic concept, and not an all-or-none phenomenon, which aims to capture inter-individual variations in biological, psychological, and behavioral responses and outcomes 
following a stressful event (Zovkic et al., 2013). From a psychological point of view, resilience can be studied in terms of constructs such as self-efficacy, optimism, positive emotions, and cognitive appraisal (Feder et al., 2019) and operationalized in terms of absent or low levels of mental health problems and sustained normal functioning during times of adversity. Some researchers have identified two components to resilience adversity and positive adaptation - but others have argued for more complex models, particularly on the basis of longitudinal studies (Cosco et al., 2017).

From a neuroscientific perspective, resilience can be defined and studied in terms of changes at the genetic, biochemical, cellular, anatomical, and physiological levels that correlate with responses to adversity, threat, or trauma (Cathomas et al., 2019; Feder et al., 2019; Gururajan et al., 2019). For example, candidate gene and genome-wide analyses have identified genetic factors that are associated with individual responses to stressful events (Stein et al., 2019; Notaras and van den Buuse, 2020); neurochemical studies have identified changes in specific neurotransmitters, such as monoamines and neuropeptides, which correlate with varying responses to stress (Averill et al., 2018); and neuroimaging studies have investigated structural and functional changes in particular brain regions that are related to stress vulnerability (Hanson et al., 2019). A useful model that bridges the conceptual gap between neuroscience and observed responses is the affiliative neuroscience approach outlined by Feldman (2018). From this perspective, which integrates biology and behavior, resilience is viewed in terms of three aspects: plasticity, which is the ability of living tissue - in this case, neural tissue to adapt to changes; sociality, which refers to the protective and stress-buffering role of social behaviors and relationships, and meaning, which is specific to humans and involves finding significance and strength in the face of suffering and also covers such constructs as spirituality and altruism. This model will be used in this paper when outlining possible links between research findings and the actual needs and experiences of healthcare workers.

\section{The Need for a Biologically Informed, Resilience-Based Approach to Mental Health, Particularly in Healthcare Workers}

In recent times, a growing awareness of the limitations of contemporary models of mental health and illness has led some researchers to critically examine the value of a resiliencebased approach to these subjects. Such an approach has already begun to yield fruit in the study of psychiatric disorders such as depression (Elisei et al., 2013; Richter-Levin and $\mathrm{Xu}, 2018$ ) and post-traumatic stress disorder (PTSD; Yehuda et al., 2016; Olff et al., 2019; Rakesh et al., 2019). Similarly, researchers in the field of child development are beginning to unravel the way in which genes, brain regions, and specific neurotransmitters influence the response of a child's brain to maltreatment or neglect. This raises the encouraging possibility of using this knowledge to promote resilience in children who have experienced deprivation (Ioannidis et al., 2020).
Such work is of direct relevance to healthcare workers, particularly during the current pandemic. Due to the specific nature of their work and the multiple stressors it may entail, these personnel are at an elevated risk of adverse mental health outcomes, and have been identified as a population that would benefit from resilience-enhancing interventions well before the COVID-19 pandemic. Available evidence suggests that certain "resilience training" programs, based on the mindfulness or cognitive-behavioral models, may have a short-term beneficial effect on perceived stress and depressive symptoms; however, a Cochrane Database systematic review found that the effect sizes for these interventions were small, and the certainty that could be attributed to any positive results was low (Kunzler et al., 2020). Moreover, a neurobiological evaluation of one such "stress management training" program found that it did not significantly alter the cortisol response to stress, and even worsened it in some participants, suggesting that such interventions may fail to achieve optimal results because they do not lead to relevant changes at the cellular or neural level (Gloster et al., 2019). In the context of such results, there is a significant need for approaches that adapt the principles of the neurobiology of resilience to the healthcare context (Llinas et al., 2018), a need that takes on a particular urgency as the world prepares itself for a "second surge" of the COVID-19 pandemic (Benham et al., 2020).

\section{The Focus of the Current Paper}

Though hundreds of papers have been published in this field in recent years, for the sake of brevity and clarity, the current paper has chosen to focus on six specific areas. These six domains are:

- The contemporary understanding of monoamine transmitter systems, particularly those involving noradrenaline and serotonin, in modulating stress response and resilience.

- The central role of psychoneuroendocrine mechanisms, particularly those involving the hypothalamic-pituitaryadrenal axis (HPA), as a putative "final common pathway" mediating vulnerability and resilience to stress.

- The key links between the immune system and the stress response, in terms of both risk and resilience.

- The epigenetic regulation of key genes involved in the stress response, and the role of this process in mediating resilience.

- The functions of certain peptide transmitters, such as neuropeptide Y (NPY) and oxytocin, in moderating the effects of stress and acting as a natural "brake" mechanism in this context.

- The neurobiological mechanisms by which environmental factors, such as early life stress, exercise, and social support, influence resilience to subsequent life events.

Three factors influenced the decision to focus on these domains. First, they have been identified as foci of particular research interest and activity in recent reviews (Fleshner et al., 2011; Wu et al., 2013; Averill et al., 2018; Feder et al., 2019). Second, they can be easily related to the affiliative neuroscience framework outlined by Feldman (2018) in a more or less 
hierarchical manner: the first two are more directly related to plasticity, while the last four provide a bridge from plasticity to sociality and meaning. Finally, and most importantly, they provide potential or actual targets for intervention that can be tested with relative ease in the current context. It is not the purpose of this article to provide a systematic review of work in this field, but rather to illustrate the potential value of this approach through certain key examples. A broad outline of these mechanisms and the interplay between them is provided in Figure 1.

\section{KEY RESEARCH AREAS IN THE NEUROBIOLOGY OF RESILIENCE AND THEIR APPLICATION TO THE COVID-19 HEALTHCARE WORKER SCENARIO}

\section{Monoaminergic Modulation of Stress and Resilience}

A consistent body of evidence supports the notion that monoamine transmitters are key modulators of human emotional and behavioral responses to stress. In the context of a prolonged traumatic situation such as the COVID-19 pandemic, the two transmitters of greatest potential significance are noradrenaline, which mediates the "flight or fight" response to stress, and serotonin, which is involved in risk appraisal and in the emotions of sadness and anxiety (Wang et al., 2020b). Variations in genes involved in regulating the function of these two transmitters, such as the catechol-O-methyltransferase (COMT) gene, the monoamine oxidase type A (MAOA) gene, the tryptophan hydroxylase type II gene (TPH2), and the serotonin transporter (SLC6A4), have been associated with significant variations in stress response and resilience in both human and animal subjects (Jabbi et al., 2007;
Clukay et al., 2019; Gonzalez-Giraldo and Forero, 2020; Strekalova et al., 2020). Research in mice suggests that the noradrenergic system plays a particular role in influencing resilience to chronic stress (Isingrini et al., 2016), and that the activation of a specific serotonin receptor subtype $\left(5 \mathrm{HT}_{4}\right)$ reduces both fear-like and depressive-like responses to chronic stress (Chen et al., 2020b). Drugs that putatively influence resilience via other receptors, such as ketamine, have also been shown to depend on intact monoamine systems for their effects in preventing stress-induced depression (Brachman et al., 2016; Bowman et al., 2020).

These effects are mediated both by the direct post-synaptic effects of these transmitters, and by their "cross-talk" with other pathways such as the midbrain dopaminergic pathway (Krystal and Neumeister, 2009), peptides such as NPY (Hokfelt et al., 2018; see section Neuropeptides), and, most significantly, the HPA "stress axis" (Ancelin et al., 2017; Prakash et al., 2020; see section The Hypothalamic-Pituitary-Adrenal Axis). Translational evidence has identified neural "final common pathways" for these effects. For example, the noradrenergic locus coeruleus (NOR-LC) system, connecting the brainstem with the amygdala, which modulates the formation and consolidation of memories related to stressful or traumatic events (Haubrich et al., 2020). Similarly, plasticity of midbrain serotonergic neurons has been associated with resilience to stress-induced depressive symptoms (Prakash et al., 2020).

At a higher level of analysis, genetic variations in serotonergic transmission have been associated with varying levels of psychological flexibility (Gloster et al., 2015), which is a key variable influencing coping strategies and stress resilience during the COVID-19 pandemic (Smith et al., 2020). Similarly, heart rate variability (HRV), a cardiac index influenced by noradrenergic transmission, is an important modulator of the neuroendocrine stress axis (Kemp and Quintana, 2013;

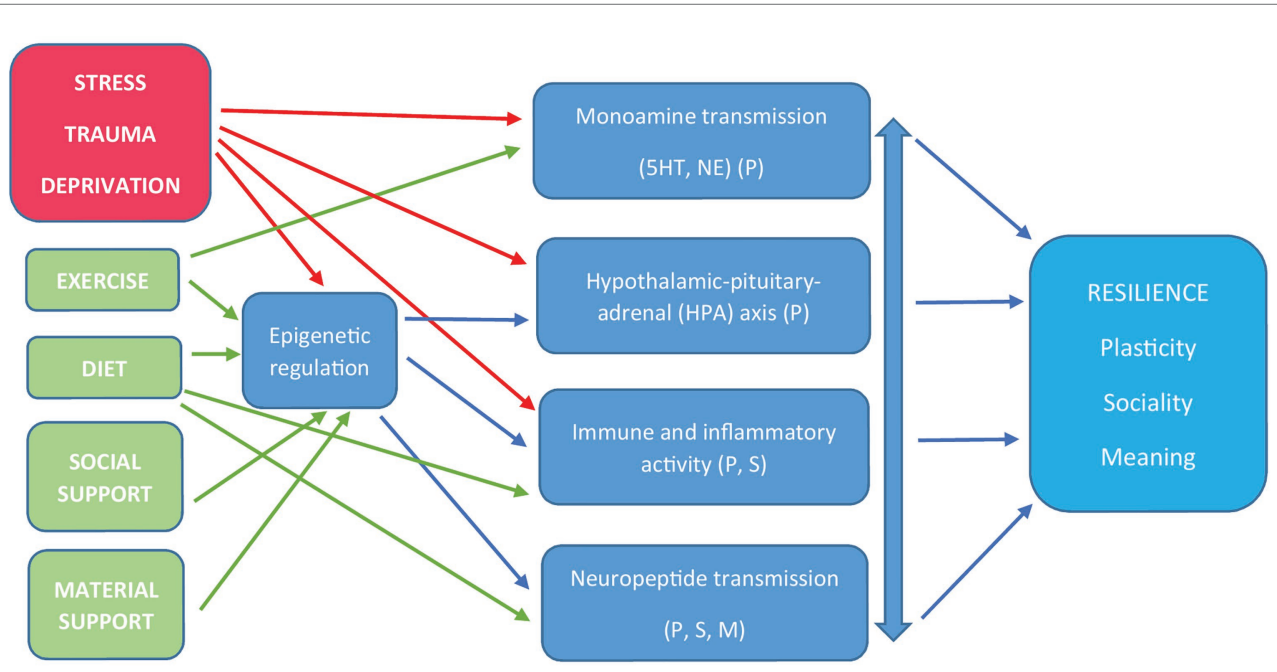

FIGURE 1 | An overview of biological mechanisms underlying stress susceptibility and resilience. Blue arrows indicate regulatory mechanisms and pathways. Red arrows indicate negative effects and green arrows indicate positive effects. Interrelations between the four common molecular mechanisms are reciprocal, as indicated by the double arrow. 5-HT, serotonin; NE, norepinephrine; HPA, hypothalamic-pituitary-adrenal; P, plasticity; S, sociality; M, meaning. 
see section Epigenetic Regulation of the Stress Response) and is itself correlated with psychological flexibility. Direct evidence for a link between these parameters was observed in a study of patients with depression, in which the level of occupancy of norepinephrine transporters by the antidepressant venlafaxine was associated with both improved resilience and increased HRV (Davidson et al., 2005). Studies of both civilians and military personnel have found that elevated levels of norepinephrine are associated with an increase subsequent risk of PTSD, while lower levels predict resilience (Highland et al., 2015). Similarly, a study of nurses working in operating rooms found that elevations in peripheral levels of norepinephrine were significantly associated with the development of posttraumatic disorder (Ke et al., 2020), and that this alteration was also associated with immune dysregulation (see section Immune-Inflammatory Influences on Stress and Resilience).

Taken together, these results suggest that variations in monoaminergic functioning can potentially influence several downstream neuroendocrine, neuroimmune, and neurocognitive processes through alterations in plasticity (Levone et al., 2015), leading to variations in stress vulnerability and resilience. It is, therefore, possible that modulation of these systems may enhance resilience in healthcare workers, particularly those exposed to stressful or traumatic situations related to the pandemic. Some of these modulation strategies are discussed in subsequent sections, but others include:

- The prophylactic or early use of antidepressant medications targeting monoamine pathways, particularly in high-risk or frontline staff. Though this approach may not be effective in all cases, there is translational evidence that it may be useful in a subgroup of individuals (Davidson et al., 2005; NietoGonzalez et al., 2015; Han et al., 2017). It is also of interest that some of these drugs have been shown to ameliorate the symptoms of COVID-19 infection, suggesting that they may be particularly useful in healthcare workers who develop COVID-19 (Lenze et al., 2020).

- The experimental use of $5 \mathrm{HT}_{4}$ receptor agonists in reducing anxiety and depressive symptoms in healthcare workers exposed to chronic stress (Chen et al., 2020b).

- The use of ketamine, already approved for the acute treatment of depression and suicidal behavior in humans, in subjects at high risk of pandemic-related stress (McGhee et al., 2008; Weinbroum, 2021); the efficacy of this drug appears to depend on intact monoamine pathways (Bowman et al., 2020).

\section{The Hypothalamic-Pituitary-Adrenal Axis}

A substantial body of research has identified the hypothalamicpituitary adrenal axis as a biological "final common pathway" on which external stress, vulnerability factors, and resilience factors converge. Recent studies have refined the understanding of the complexities involved in HPA axis functioning and regulation (Frodl and O'Keane, 2013). Apart from the established links between HPA axis dysregulation and several common mental disorders (Zorn et al., 2017), recent research has outlined the role of this neuroendocrine pathway in phenomena such as burnout (Kakiashvili et al., 2013; Chow et al., 2018), maladaptive work-related attitudes and practices (Eddy et al., 2018), and responses to discrimination (Busse et al., 2017). These three facets are of particular importance to the situation of healthcare workers during the COVID-19 pandemic, in which chronic workplace stress, high demands and expectations, and stigma related to the risk of infection can all contribute to adverse mental health outcomes (da Silva and Neto, 2020; Dobson et al., 2020; Pappa et al., 2020; Sotgiu and Dobler, 2020; Taylor et al., 2020a). In general, increased workplace stress and a perceived lack of proportionate rewards lead to HPA axis overactivity (Eddy et al., 2018), but in the long run, prolonged stress leading to burnout results in relatively low cortisol levels, despite elevations in corticotrophin-releasing hormone (CRH). These endocrine changes lead to alterations in the methylation of key genes moderating stress response and resilience, such as the glucocorticoid receptor (NR3C1) and brain-derived neurotrophic factor (BDNF) genes, and to lower levels of BDNF which impair neural plasticity and correlate with the severity of burnout (Bakusic et al., 2017). Relative hypocortisolism is also seen in PTSD, while relative over-activation is seen in depression. Both these conditions are often observed in healthcare workers during the COVID-19 pandemic (Chew et al., 2020).

Recent neurobiological advances provide a number of promising leads for interventions that can positively modulate HPA axis functioning, thereby minimizing the risk of burnout as well as mental disorders in healthcare workers. For example, it has been shown that there is a close link between HRV, a measure of decreased parasympathetic and increased sympathetic nervous system functioning, and regulation of the HPA axis. Reduced HRV is associated with greater dysregulation, and is correlated with impairments in psychological flexibility, social cognition, and resilience to stress (Kemp and Quintana, 2013). Interventions that normalize HRV may lead to improved HPA axis functioning, and protect healthcare workers from a variety of adverse outcomes. A similar relationship has been identified between human circadian rhythms and the HPA axis response to stress; sleep deprivation and frequent changes in sleep-wake schedule can all contribute to dysfunction of this pathway, leading to reduced resilience (Kinlein and Karatsoreos, 2020). This aspect is of particular relevance to healthcare workers involved in frontline or intensive care duties during the COVID-19 pandemic. Finally, the downstream effects of HPA axis dysregulation appear to be related to reduced expression of glucocorticoid receptors (GR) in the hippocampus, a change that can potentially be reversed by pre-treatment with antidepressants in animal models of stress (Han et al., 2017). The latter finding underlines the close links between the HPA axis and monoamine transmission, as discussed in section Monoaminergic Modulation of Stress and Resilience.

Given these complexities, direct pharmacological modulation of the HPA axis may not always yield the expected results, though they may have a role in specific cases. For example, antagonism of CRF receptors would theoretically be expected to enhance resilience; however, CRF-1 antagonists have yielded disappointing results in human subjects to date (Spierling and Zorrilla, 2017). On the other hand, there is promising evidence from controlled 
clinical trials that administration of low-dose hydrocortisone in the immediate aftermath of trauma could attenuate or even prevent PTSD in inpatients with physical illnesses, perhaps by correcting relative hypocortisolism (Astill Wright et al., 2019). This approach may be useful in healthcare workers who are themselves hospitalized for COVID-19.

In real-world settings, these findings suggest several promising avenues for building resilience and countering the effects of stress on healthcare workers, through behavioral or pharmacological modulation of the several factors influencing HPA axis functioning. These interventions can be seen as working chiefly at the level of plasticity in Feldman (2018) model Bakusic et al. (2017). Possibilities include:

- The use of techniques that correct reduced HRV, thereby enhancing resilience through HPA axis modulation. These include exercise (Kemp and Quintana, 2013), mindfulnessbased interventions (Radmark et al., 2019), yoga-based techniques centered on breathing (Nivethitha et al., 2016), and guided relaxation (Lewis et al., 2015). There is already considerable evidence that such techniques produce significant changes in HPA axis functioning when implemented in workplace settings (Heckenberg et al., 2018).

- Organizational changes aimed at correcting environmental or workplace factors that can contribute to HPA axis dysregulation in the long run. These include due attention to shift work hours to minimize impacts on individual healthcare workers, and efforts to reduce the stigmatization or isolation of those who work with COVID-19 patients and are wrongly viewed as "dangerous" or "infectious" (Taylor et al., 2020a).

- Counseling or self-help techniques aimed, not at general stress reduction, but at correcting factors such as psychological inflexibility and overcommitment to work which are associated with HPA axis dysfunction (Eddy et al., 2018; Guevara and Murdock, 2020) as well as with adverse mental health outcomes in the context of COVID-19 (Landi et al., 2020; Smith et al., 2020). This would regulate this neuroendocrine pathway in a "top-down" manner.

- More speculatively, the use oflow-dose steroids in healthcare workers exposed to severe trauma, as this approach has been shown to prevent the development of subsequent PTSD in both translational models and clinical settings (Zohar et al., 2011; Astill Wright et al., 2019).

\section{Immune-Inflammatory Influences on Stress and Resilience}

Over the past three decades, substantial evidence has accumulated on the close links between immune system functioning, responses to stress, and resilience (Breen et al., 2015; Dantzer et al., 2018; Gururajan et al., 2019). Changes in several inflammatory markers, such as elevations in C-reactive protein (CRP), lowered levels of the cytokines interferon-gamma (IFN $\gamma$ ) and tumor necrosis factor-alpha (TNF $\alpha)$, and elevated levels of the chemokines CCL13, CCL20, and CXCL6 have all been associated with an increased risk of PTSD following exposure to traumatic stressors (Eraly et al., 2014; Michopoulos et al., 2020; Zhang et al., 2020a).
Conversely, lower levels of interleukin-6 (IL-6) and elevations of the chemokine CX3CL1 have been identified as potential markers of resilience (Imai et al., 2019; Zhang et al., 2020a). In a more general manner, research in animals has shown that exposure to social stress is associated with increase in levels of specific cytokines (IL-2, IL-6, IL-10, IL-17A, IL-22, and $\mathrm{TNF} \alpha$ ), and these changes are correlated with behavioral responses to stress, and these changes have been associated with reduced neurogenesis and synaptic plasticity (Hodes et al., 2014; Muhie et al., 2017). Given this finding, as well as the intimate reciprocal links between immune and HPA axis functioning in response to experimental models of social stress (Page et al., 2014), it is plausible that alterations in immune function can affect individual resilience at the levels of both plasticity and sociality. Thus, alterations in immune-inflammatory functioning may represent a mechanism linking both these dimensions. Preliminary evidence in humans has also found evidence of a close link between exposure to social stress and changes in both cortisol and IL-6 levels, which in turn can affect neural plasticity and subsequent responses to adversity (Chen et al., 2017).

As is the case with the HPA axis, there are several promising possibilities for modulating stress-induced changes in immune function and thereby enhancing resilience. From a top-down perspective, reducing social isolation - a particular problem in healthcare workers dealing with the pandemic - has been associated with beneficial changes in peripheral inflammatory markers (Yang et al., 2014; Ahmadian et al., 2020). Similar beneficial effects on immune function have been observed with exercise and dietary changes, as discussed in section Environmental Influences on Resilience: Neurobiological Principles below. From a bottom-up perspective, animal models have shown that immunization with specific substances, such as myelin-related peptides (Lewitus et al., 2008), and certain mycobacterial strains (Reber et al., 2016; Loupy et al., 2021) can attenuate stress-induced anxiety and promote resilience via alterations in immune functioning, such as inhibition of stressrelated increases in IL-6. The latter finding is of particular significance in the context of the COVID-19 pandemic, as it has been noted that immunization against Mycobacterium tuberculosis exerts a potential protective effect against COVID-19 mortality (Li, 2021) and trials of BCG immunization in healthcare workers for this purpose are in progress (Junqueira-Kipnis et al., 2020; Madsen et al., 2020). Stress-induced alterations in immune function are also under epigenetic control and may be amenable to modulation in this manner, as discussed in the next section.

The implications of these findings for healthcare workers are that it may be possible to identify healthcare workers at a higher risk of adverse outcomes in response to stress by measuring immune-inflammatory markers, and to enhance resilience in staff to stress by direct or indirect modulation of the immune system. Approaches of possible merit in this regard include:

- Examining the predictive value of immune markers already identified as markers of stress (high CRP, low IFN $\gamma$, and $\mathrm{TNF} \alpha$ ) or resilience (low IL6 and elevated CX3CL1) in prospective studies of healthcare workers. 
- Reducing peripheral inflammatory activity by minimizing social isolation and loneliness and fostering mutual and institutional support for healthcare workers.

- Changes in dietary pattern and exercise (discussed in section Environmental Influences on Resilience: Neurobiological Principles below).

- More experimentally, assessing whether BCG immunization is associated with enhanced resilience in data from ongoing clinical trials in healthcare workers, and if this proves to be the case, conducting cautious further trials with this specific outcome in mind.

\section{Epigenetic Regulation of the Stress Response}

Early research into the genetics of resilience focused on candidate genes that were thought to influence the responsiveness of the stress axis, such as monoamine transmitters or HPA axis-related receptors (Jabbi et al., 2007; Derijk and de Kloet, 2008) and then grew to encompass the role of multiple gene-environment interactions, and other genetic variants (Daskalakis et al., 2013). Subsequent studies focused on more downstream molecular mediators of resilience.

A subsequent group of studies focused on molecules that were further downstream in the signal of inter- and intracellular signaling, such as brain-derived neurotrophic factor (BDNF; Notaras and van den Buuse, 2020) as well as genome-wide analyses which have identified novel genes related to psychological resilience, such as doublecortin-like kinase 2 (DCLK2) and kelch-like family member 36 (KLHL36; Stein et al., 2019). Most of these novel candidates are associated with neuronal integrity and plasticity; thus, these results are in line with a Feldman's model, in which cellular plasticity is a key mediator of resilience (Feldman, 2018).

However, research into mental disorders such as major depression and PTSD has underlined the key role of geneenvironment $(\mathrm{GxE})$ interactions in determining the relationship between genetic variants and mental health outcomes, in what may be termed "two-hit" (genotype $\mathrm{x}$ environmental stress) or "three-hit" (genotype x early life adversity x current stress) models (Daskalakis et al., 2013; Zannas and West, 2014). In other words, while genetic variants and childhood adversity may impair resilience, these effects can be buffered by interventions in the "here and now." A key mechanism underlying this buffering effect is the epigenetic modification of key genes by a variety of environmental factors. These modifications involve chemical changes such as DNA methylation that alter gene transcription and expression without any changes in the actual nucleotide sequence. Environmental stress has been found to exert a marked influence on these processes, both through effects on proteins that regulate methylation, and through effects on "reader" proteins such as methyl-CpG binding protein 2 (MECP2) that link DNA methylation to transcriptional activity in key genes, such as the FKBP5 gene which regulates HPA axis functioning (Reul et al., 2014; Zannas and West, 2014). In fact, it has been suggested that the typical physiological and behavioral responses to stress and trauma in humans are largely caused by epigenetic changes common to many mammals, particularly in genes regulating immune function (Sipahi et al., 2014). Both experimental models of social stress (Nasca et al., 2019) and experiences of stress in real-world settings (ArzateMejia et al., 2020) have been associated with demonstrable changes in DNA methylation patterns. In other words, epigenetic mechanisms are another pathway linking the resilience dimensions of plasticity and sociality in the Feldman's model.

These changes can, in turn, be potentially reversed through appropriate behavioral, psychological, or even pharmacological interventions, providing a further potential target for interventions aimed at enhancing resilience which can be objectively assessed by measuring changes in DNA methylation (Pape et al., 2018; Gottschalk et al., 2020). Such changes have already been documented for interventions such as meditation (Kaliman, 2019) and psychological therapies (Roberts et al., 2015; Kumsta, 2019), and may prove useful in identifying those who would best profit from such approaches. Beneficial epigenetic changes in GR genes have also been observed in response to psychological interventions in patients with PTSD (Castro-Vale and Carvalho, 2020). It has also been observed that a phytochemical product, dihydrocaffeic acid (DHCA), promotes stress resilience in mice by inhibiting DNA methylation of the interleukin-6 gene (IL6; Wang et al., 2018) though such a finding requires replication and testing in human subjects, it represents a promising future intervention strategy for healthcare workers.

In real-world terms, the chief implication of these studies for healthcare workers is that vulnerability to stress is partly genetically determined, but can be moderated by behavioral and environmental modification. Potential epigenetics-based approaches in this population could include:

- Assessing changes in methylation of key stress axis genes (BDNF, glucocorticoid receptors, and FKBP5) in healthcare workers experiencing stress-induced symptoms of anxiety, depression and PTSD, as well as in those making use of workplace stress-reduction programs.

- Provision of early specific trauma-related counseling to frontline healthcare workers, or those showing early signs of traumatic stress while on COVID-19 duty (Castro-Vale and Carvalho, 2020).

- Environmental changes, particularly the provision of emotional and material support (Miller et al., 2015; Shields et al., 2016), which may reverse stress-induced epigenetic changes.

- Experimentally, trials of drugs known to have a positive effect on epigenetic modulation of the HPA axis, immune system, or neuronal plasticity, such as antidepressants (Muñoz-Cobo et al., 2018), antagonists of the corticotropin-releasing factor 1 (CRF) receptor (Pape et al., 2018), and phytochemicals (Wang et al., 2018).

\section{Neuropeptides}

Over the last two decades, a significant body of evidence has accumulated on the key role of neuropeptides in a variety of mental disorders, including anxiety disorders, obsessive-compulsive 
disorder, PTSD, eating disorders, depression, and alcohol dependence (Bandelow et al., 2017; Harper et al., 2018; Plessow et al., 2018; Shariq et al., 2019). This association may be explained by the fact that neuropeptides co-exist with "classic" neurotransmitters (such as serotonin or dopamine) within neurons, and themselves act as transmitters, neurotrophic factors, and regulators of "classic" neural transmission (Hokfelt et al., 2018). As many of these disorders are triggered or exacerbated by stress, it stands to reason that neuropeptides may prove to be key mediators of resilience at the cellular level. Moreover, neuropeptides are important regulators of social behavior and bonding (MeyerLindenberg et al., 2011), making them of direct relevance to the social dimension of resilience, particularly in the context of the COVID-19 pandemic where social distancing, quarantine, and reduced social support all exert a negative impact on the mental health of healthcare workers (da Silva and Neto, 2020). Specific neuropeptides have also been strongly correlated with individual variations, religious, and spiritual beliefs (Imamura et al., 2017; Tonnesen et al., 2018), suggesting that - uniquely among the mechanisms discussed thus far - they are also related to the meaning dimension of resilience. In other words, from a conceptual viewpoint, neuropeptides are implicated in all three of Feldman's postulated dimensions of resilience.

Among the various neuropeptides of interest, the most attention has been given to NPY, a 36-amino acid peptide which is widely distributed in the central nervous system. The effects of NPY on resilience are complex: activation of type 1 (Y1) NPY receptors reduces anxiety and mediates resilience, while activation of type 2 (Y2) receptors increase anxiety. On the whole, NPY is considered to have a protective effect against stress, by counteracting the actions of the peptide corticotrophin-releasing hormone (CRH) which activates the "stress axis" (Wu et al., 2013; Reichmann and Holzer, 2016). Administration of NPY reduces submissive and defensive behaviors in male hamsters subjected to social defeat; this effect persisted even after experimental blockade of Y1 receptors, suggesting that other NPY receptor subtypes play an important role in resilience (Lacey et al., 2019). In human subjects, plasma and cerebrospinal fluid levels of NPY correlate negatively with levels of post-traumatic stress in military veterans (Sah et al., 2014), and a functional polymorphism (rs16147) of the NPY gene was found to interact with trauma exposure to predict resilience in adults, with the $T$ allele conferring a protective role (Gan et al., 2019). Though NPY represents an attractive molecular target for the enhancement of resilience, its effectiveness has not yet been tested in formal pharmacological trials. However, the NPY pathway may be indirectly targeted through modification of gut microbiota or inflammatory activity through the use of probiotics or dietary modification, as gut inflammation has been associated with reduced NPY levels in key brain regions related to stress, such as the hippocampus and amygdala (Holzer et al., 2012).

Besides NPY, a number of neuropeptides have been identified as potential mediators of resilience at the cellular level as well as in terms of influencing adaptive social behavior - in other words, as moderators of plasticity and sociality.
One of the most prominent of these peptides is oxytocin, which appears to exert a regulatory effect on the cortisol response to stress (Li et al., 2019; Winter and Jurek, 2019). In addition, it has been shown to reduce depressive symptoms following loss of a partner in animal models (Bosch and Young, 2018), to reduce brain responses to fear-provoking visual stimuli in human suffering already exposed to trauma (Flanagan et al., 2019), and to potentially enhance the likelihood of engaging in altruistic or pro-social behaviors (Hurlemann, 2017). These effects are all relevant to the COVID-19 pandemic, where healthcare workers often experience interpersonal separation, social isolation, and a heightened exposure to fear-generating cues. Polymorphisms of the oxytocin receptor gene have also been found to influence vulnerability to PTSD (Sippel et al., 2017). These findings suggest that the administration of oxytocin - which is already used as a pharmacological agent in obstetric settings, and as an experimental adjunct to psychological therapies (Domes et al., 2019) - may be effective in increasing resilience and reducing the risk of stress-related mental disorders (Sharma et al., 2020).

Other peptides which have been shown to influence resilience and stress responses, though at a much more preliminary level of evidence, include the endogenous opioid family of enkephalins (Nam et al., 2019), orexin (Staton et al., 2018; Summers et al., 2020), nociceptin (Narendran et al., 2019), somatostatin (Stengel and Tache, 2017), and galanin (Sciolino et al., 2015). These peptides have been shown to enhance resilience in animal models during experimental stress-inducing procedures, and to influence other molecules of key importance in brain resilience, such as BDNF. However, their exact role and significance in humans, and more particularly in the specific situations faced by healthcare workers during the COVID-19 pandemic, requires further investigation.

In real-world settings, the significance of the above findings lies in the potential to augment resilience to stress, both at the neural and the social levels, through direct (pharmacological) or indirect (diet and exercise) manipulation of brain neuropeptide transmission. Potential roles for neuropeptide-based interventions in this setting could include:

- The use of lifestyle modifications, such as diet-based interventions or physical exercise, in enhancing the effects of peptides such as NPY and galanin in boosting resilience (Holmes, 2014; Farzi et al., 2015).

- The potential for direct pharmacotherapy using intranasal oxytocin to enhance pro-social behavior and resilience in healthcare workers, either alone or as an adjunct to psychological or behavioral interventions (Koch et al., 2014).

- The possibility of using opioid-based therapies to attenuate the effects of social stress and isolation - "social pain" - in healthcare workers facing specific situations, such as prolonged hours away from home or quarantine, via modulation of endogenous opioid receptors. Though a caveat must be raised regarding the possibility of abuse in this context, such treatments may be effective even when used at low doses for short periods of time (Yovell et al., 2016). 


\section{Environmental Influences on Resilience: Neurobiological Principles}

The foregoing sections have provided an overview of the myriad biological mechanisms that influence resilience, the relationships between them, and their links to the resilience dimensions of plasticity, sociality, and meaning, particularly in the context of the COVID-19 pandemic. In discussing these, frequent mentions have been made of the influence of environmental factors on the regulation of these processes. It is useful to revisit some of these links from a neurobiological perspective for two reasons. First, certain lifestyle or environmental modifications that have been shown to correlate with specific biological changes, which in turn can be used to objectively assess the effect of such interventions in terms of parameters such as HPA axis functioning, DNA methylation, altered levels of immune markers, or regional brain activity. Second, the knowledge of these correlates could lead to a more purposeful approach to designing and implementing programs to boost resilience in the face of a major crisis, such as the COVID-19 pandemic. Keeping these two objectives in mind, the following are specific domains where experimental knowledge of the biological correlates of resilience and feasible interventions for healthcare workers intersect:

\section{Exercise}

Regular physical exercise interacts with genetic vulnerability to minimize the risk of post-traumatic stress symptoms, increases HRV, and may positively influence the activity of resiliencepromoting neuropeptides. The final common pathway for all these effects may be the expression of the BDNF gene in key brain areas involved in resilience, such as the hippocampus and prefrontal cortex, leading to increased local BDNF levels and enhancement of neurogenesis and neural plasticity (Taliaz et al., 2011; Holmes, 2014). In addition, exercise may partially reversing stress-induced changes in immune function (Wang et al., 2020a). Exercise can also exert a beneficial effect on physical health in the context of COVID-19, and the amount of exercise required to achieve these effects - about 15-20 min of walking or other moderate activity per day - is well within the range of what is practical for healthcare workers (Simpson and Katsanis, 2020; Wang et al., 2020a). This aspect is sometimes passed over in standard "stress management" packages for healthcare workers (Chen et al., 2020a), but there are few significant obstacles to its inclusion.

\section{Diet}

Though firm evidence for a translational link between the gut-brain axis and resilience in humans is lacking (Tooley, 2020), there is evidence that specific nutrients (Toyoda, 2020) or probiotics (Maehata et al., 2019; Westfall et al., 2021) may modulate stress resilience in animal models, most probably by influencing immune function. There is some preliminary evidence to support such an effect in humans (Taylor et al., 2020b), and this approach may be beneficial when planning meals for healthcare workers. Similarly, healthy eating behaviors may be encouraged by instruction and example (Zheng et al., 2020).

\section{Housing and Shelter}

Animal models have provided a preliminary picture of the complex relationship between housing and stress. In young rodents, but not in adults, single housing is associated with elevated stress compared to group housing. In adult rodents, paired housing evokes a greater stress response than group housing. These effects appear to correlate with the level of expression of the glucocorticoid receptor gene $\mathrm{NR} 3 \mathrm{Cl} 1$ in the hippocampus (Pan-Vazquez et al., 2015). In addition, the provision of an enriched environment during group housing - which, in animal models, refers to the provision of toys and running wheels - also minimizes the impact of external stressors (van Praag et al., 2000; Huzard et al., 2015). These considerations may be particularly relevant to the living conditions of healthcare workers during the COVID-19 pandemic, where the social isolation caused by individual accommodation (for example, during quarantine) may worsen stress, and the provision of group rest areas and leisure activities may foster resilience.

\section{Sleep}

Stress has both subjective and objective effects on sleep quantity, quality, and structure, which appear to be mediated by changes in metabotropic glutamate receptor functioning in limbic brain regions (Highland et al., 2019; Sweeten et al., 2021). In addition, sleep deprivation leads to reduced hippocampal neurogenesis and plasticity, potentially impairing resilience to stress (Saletin et al., 2016). In healthcare workers already dealing with long hours or frequent changes in shifts due to the COVID-19 pandemic, these two effects may form a self-reinforcing process, in which sleep deprivation lowers resilience, leading to an increased impact of stress on sleep (Huffmann et al., 2020; Salari et al., 2020). Administrative policies to miminize frequent changes in sleep patterns or prolonged shift work, as well as individual or group behavioral interventions to improve sleep hygiene and sleep-related practices, may prove helpful in minimizing the impact of sleep disruptions on resilience in this population (Elder et al., 2020; Muller et al., 2020; Rajkumar, 2020).

\section{Social Support}

Evidence from animal research has shown that social involvement, such as the presence of cage mates of the same species during experimental models of stress, significantly increases adaptive behaviors and facilitates fear extinction. These resilience-enhancing effects appear to be associated with changes in the expression of immediate early genes, such as fos (Colnaghi et al., 2016). On the other hand, overcrowding, isolation, social defeat, and "social instability" (alternating crowding and isolation) can result in increases in endocrine and behavioral responses to stress in rodent models, an effect which may be partially mediated by the neuropeptide CRH (Beery and Kaufer, 2015) or altered immune functioning (Page et al., 2014). There is evidence that social support is inversely associated with psychological distress in healthcare workers during the COVID-19 pandemic (Alizadeh et al., 2020; Nowicki et al., 2020). In this context, ensuring adequate opportunities for socialization with colleagues, family members, and friends, while adhering to appropriate infection control guidelines, can help in fostering resilience in healthcare workers at the individual and team level, as can attempts to minimize the stigmatization faced by these personnel (Taylor et al., 2020a). 


\section{Economic and Food Security}

Rodent models suggest that scarcity of material resources, such as food, can alter HPA axis functioning and DNA methylation patterns, leading to disturbances in neuroendocrine functioning and social behavior (Perry et al., 2019; Pertille et al., 2020); similar alterations in stress axis functioning in response to poverty or disadvantageous environments have been noted in human children (Finegood et al., 2017) and adults (Sullivan et al., 2019). For a variety of reasons, including work timings, business closures, and stigmatization, healthcare workers may experience insecurity in terms of food, material needs, and income during the COVID-19 pandemic (Cotrin et al., 2020; Larson et al., 2020), particularly in low- and middle-income countries (Onigbinde et al., 2020). Organizational policies that assist healthcare workers in this aspect, both at the workplace and in their homes, may be useful in normalizing endocrine responses to stress and enhancing resilience.

There are several other factors that may be considered in this regard, including the effect of larger-scale social changes, such as those caused by a pandemic, on biomarkers of stress and resilience (Thomaes et al., 2016). However, the purpose of this review is to focus on aspects of environmental change that are supported by translational evidence, and which can be implemented within a reasonable time frame at the institutional or workplace level.

\section{CONCLUSION: A CAUTIONARY TALE, REVISITED}

In the light of the foregoing evidence (see Figure 1), it is now possible to understand what was lacking in the healthcare worker wellness program described in Chen et al. (2020a) and how subsequent modifications substantially improved its acceptability efficacy. Though done unknowingly, many of the changes made in the second wave of this program - the provision of a common rest area and leisure activities, ensuring security in terms of food and other essential supplies, and periodic visits for the purpose of support or counseling - are entirely in line with measures to combat stress and enhance resilience that have proved valuable in experimental models. This is particularly true with reference to the studies summarized section Environmental Influences on Resilience: Neurobiological Principles above, in which exercise, leisure, sleep, and social support can all positively influence the biological and behavioral response to external stress, through mechanisms that are outlined in sections "Monoaminergic Modulation of Stress and Resilience, The Hypothalamic-Pituitary-Adrenal Axis, Immune-Inflammatory Influences on Stress, and Resilience, Epigenetic Regulation of the Stress Response, and Neuropeptides." However, it is possible to go beyond this. Future programs aimed at building resilience in healthcare workers during and after the COVID-19 pandemic should be multifaceted, and consider the possibility of other neurobiologically-informed approaches to stress modulation, which may include dietary modification, the use of probiotics, mindfulness-based approaches, and even the judicious use of pharmacological agents such as oxytocin, low-dose cortisol, antidepressants, ketamine, or ultra-low-dose opioid agonists in selected cases. This biologically informed approach can also be fruitfully linked with the psychotherapeutic approach advocated by Rosen et al. (2020) - for example, by developing individual or group educational and counseling programs for healthcare workers that focus on specific constructs such as psychological flexibility or the avoidance of overcommitment. Finally, specific biomarkers - involving not only "classical" HPA axis parameters but levels of neuropeptides, genetic polymorphisms, epigenetic alterations, and measures of regional brain activity - could be used both to identify those at high risk of psychological distress, who would benefit from more intensive or sustained interventions, and to obtain objective correlates of the effectiveness of the strategies outlined above. In a context such as the COVID-19 pandemic, it is impossible to avoid stress altogether; moreover, the avoidance of stressors may actually lower resilience (Katz et al., 2019). What is needed is a comprehensive set of approaches that work synergistically to enable healthcare workers to maintain an adaptive level of functioning while minimizing psychological distress, and there is good reason to believe that the methods described in the preceding sections may be valuable additions to this set. Due to space constraints, other neurobiological mediators of resilience, such as the neurotransmitters gamma-amino butyric acid and glutamate (Wagner et al., 2015; Ardi et al., 2019) and the role of microRNAs in influencing the expression of stress-related genes and resilience (Issler et al., 2014), could not be covered in depth; however, they also represent promising future avenues for research and intervention in this field.

In conclusion, there are enough promising leads from both human and animal research - some of which are already being confirmed through field reports, preliminary clinical trials, or both - to suggest that harnessing the potential of the neurobiology of resilience, and placing it at the service of healthcare workers burdened by the COVID-19 pandemic and its attendant stressors, is feasible and may prove to be more efficacious than conventional approaches based on expert opinion. A major challenge for the future will be to integrate these findings into existing services aimed at addressing the mental health needs of healthcare workers, and adapting them to cultural realities as well as to economic and logistic constraints. To ensure the validity of such approaches, both biomarker-based and psychometrically assessed aspects of stress and resilience must be adopted as outcome measures when assessing them in real-world settings.

\section{AUTHOR CONTRIBUTIONS}

The author developed the concept for this review, carried out the literature search, wrote the paper, and proofread it. This paper represents the author's original work and has not been submitted for publication elsewhere.

\section{ACKNOWLEDGMENTS}

I wish to thank all researchers and publishers who have made their work freely accessible during the COVID-19 pandemic. 


\section{REFERENCES}

Ahmadian, A. J., Lin, J. E., Neylan, T. C., Woolley, J. D., O’Donovan, A., and Cohen, B. E. (2020). Social integration and inflammation in individuals with and without posttraumatic stress disorder. Brain Behav. Immun. 89, 168-174. doi: 10.1016/j.bbi.2020.06.013

Alizadeh, A., Khankeh, H. R., Barati, M., Ahmadi, Y., Hadian, A., and Azizi, M. (2020). Psychological distress among Iranian health-care providers exposed to coronavirus disease 2019 (COVID-19): a qualitative study. BMC Psychiatry 20:494. doi: $10.1186 / \mathrm{s} 12888-020-02889-2$

Ancelin, M. -L., Scali, J., Norton, J., Ritchie, K., Dupuy, A. -M., Chaudieu, I., et al. (2017). Heterogeneity in HPA axis dysregulation and serotonergic vulnerability to depression. Psychoneuroendocrinology 77, 90-94. doi: 10.1016/j. psyneuen.2016.11.016

Ardi, Z., Richter-Levin, A., Xu, L., Cao, X., Volkmer, H., Stork, O., et al. (2019). The role of the GABAA receptor alpha 1 subunit in the ventral hippocampus in stress resilience. Sci. Rep. 9:13513. doi: 10.1038/s41598-019-49824-4

Arzate-Mejia, R. G., Lottenbach, Z., Schindler, V., Jawaid, A., and Mansuy, I. M. (2020). Long-term impact of social isolation and molecular underpinnings. Front. Genet. 11:589621. doi: 10.3389/fgene.2020.589621

Astill Wright, L., Sijbrandij, M., Sinnerton, R., Lewis, C., Roberts, N. P., and Bisson, J. I. (2019). Pharmacological prevention and early treatment of posttraumatic stress disorders and acute stress disorder: a systematic review and meta-analysis. Transl. Psychiatry 9:334. doi: 10.1038/s41398-019-0673-5

Averill, L. A., Averill, C. L., Kelmendi, B., Abdallah, C. G., and Southwick, S. M. (2018). Stress response modulation underlying the psychobiology of resilience. Curr. Psychiatry Rep. 20:27. doi: 10.1007/s11920-018-0887-x

Bakusic, J., Schaufeli, W., Claes, S., and Godderis, L. (2017). Stress, burnout and depression: a systematic review on DNA methylation mechanisms. J. Psychosom. Res. 92, 34-44. doi: 10.1016/j.jpsychores.2016.11.005

Bandelow, B., Baldwin, D., Abelli, M., Bolea-Alamanac, B., Bourin, M., Chamberlain, S. R., et al. (2017). Biological markers for anxiety disorders, OCD and PTSD: a consensus statement. Part II: neurochemistry, neurophysiology and neurocognition. World J. Biol. Psychiatry 18, 162-214. doi: 10.1080/1562 2975.2016.1190867

Beery, A. K., and Kaufer, D. (2015). Stress, social behavior, and resilience: insights from rodents. Neurobiol. Stress 1, 116-127. doi: 10.1016/j.ynstr. 2014.10.004

Benham, T. L., Hart, A., Bortolin, M., Court, M., Groves, J., Kraus, A., et al. (2020). Preparing for the second surge: preventing posttraumatic stress disorder and building resilience for healthcare workers in the face of COVID-19. Disaster Med. Public Health 1-14. doi: 10.1017/dmp.2020.371

Bosch, O. J., and Young, L. Y. (2018). Oxytocin and social relationships: from attachment to bond disruption. Curr. Top. Behav. Neurosci. 35, 97-117. doi: 10.1007/7854_2017_10

Bowman, M. A., Vitela, M., Clarke, K. M., Koek, W., and Daws, L. C. (2020). Serotonin transporter and plasma membrane monoamine transporter are necessary for the antidepressant-like effects of ketamine in mice. Int. J. Mol. Sci. 21:7581. doi: 10.3390/ijms21207581

Brachman, R. A., McGowan, J. C., Perusini, J. N., Lim, S. C., Pham, T. H., Faye, C., et al. (2016). Ketamine as a prophylactic against stress-induced depressive-like behavior. Biol. Psychiatry 79, 776-786. doi: 10.1016/j.biopsych. 2015.04.022

Breen, M. S., Maihofer, A. X., Glatt, S. J., Chandler, S. D., Tsuang, M. T., Risbrough, V. T., et al. (2015). Gene networks specific for innate immunity define post-traumatic stress disorder. Mol. Psychiatry 20, 1538-1545. doi: 10.1038/mp.2015.9

Busse, D., Yim, I. S., Campos, B., and Marshburn, C. K. (2017). Discrimination and the HPA axis: current evidence and future directions. J. Behav. Med. 40, 539-552. doi: 10.1007/s10865-017-9830-6

Castro-Vale, I., and Carvalho, D. (2020). The pathways between cortisol-related regulation genes and PTSD psychotherapy. Healthcare 8:E376. doi: 10.3390/ healthcare 8040376

Cathomas, F., Murrough, J. W., Nestler, E. J., Han, M.-H., and Russo, S. J. (2019). Neurobiology of resilience: interface between mind and body. Biol. Psychiatry 86, 410-420. doi: 10.1016/j.biopsych.2019.04.011

Chen, X., Gianferante, D., Hanlin, L., Fiksdal, A., Breines, J. G., Thoma, M. V., et al. (2017). HPA-axis and inflammatory reactivity to acute stress is related with basal HPA-axis activity. Psychoneuroendocrinology 78, 168-176. doi: 10.1016/j.psyneuen.2017.01.035

Chen, Q., Liang, M., Li, Y., Guo, J., Fei, D., Wang, L., et al. (2020a). Mental health care for medical staff in China during the COVID-19 outbreak. Lancet Psychiatry 7, e15-e16. doi: 10.1016/S2215-0366(20)30078-X

Chen, B. K., Mendez-David, I., Luna, V. M., Faye, C., Gardier, A. M., David, D. J., et al. (2020b). Prophylactic efficacy of 5-HT4R agonists against stress. Neuropsychopharmacology 45, 542-552. doi: 10.1038/s41386-019-0540-3

Chew, N. W. S., Lee, G. K. H., Tan, B. Y. Q., Jing, M., Goh, Y., Ngiam, N. J. H., et al. (2020). A multinational, multicentre study on the psychological outcomes and associated physical symptoms amongst healthcare workers during COVID-19 outbreak. Brain Behav. Immun. 88, 559-565. doi: 10.1016/j. bbi.2020.04.049

Chow, Y., Masiak, J., Mikolajewska, E., Mikolajewski, D., Wojcik, G. M., Wallace, B., et al. (2018). Limbic brain structures and burnout: a systematic review. Adv. Med. Sci. 63, 192-198. doi: 10.1016/j.advms.2017.11.004

Clukay, C. J., Dajani, R., Hadfield, K., Quinlan, J., Panter-Brick, C., and Mulligan, C. J. (2019). Association of MAOA genetic variants and resilience with psychosocial stress: a longitudinal study of Syrian refugees. PLoS One 14:e0219385. doi: 10.1371/journal.pone.0219385

Colnaghi, L., Clemenza, K., Groleau, S. E., Weiss, S., Snyder, A. M., Lopez-Rosas, M., et al. (2016). Social involvement modulates the response to novel and adverse life events in mice. PLoS One 11:e0163077. doi: 10.1371/journal.pone.0163077

Cosco, T. D., Kaushal, A., Hardy, R., Richards, M., Kuh, D., and Stafford, M. (2017). Operationalising resilience in longitudinal studies: a systematic review of methodological approaches. J. Epidemiol. Community Health 71, 98-104. doi: $10.1136 /$ jech-2015-206980

Cotrin, P., Moura, W., Gambardela-Tkacz, C. M., Pelloso, F. C., Dos Santos, L., Carvalho, M. D. d. B., et al. (2020). Healthcare workers in Brazil during the COVID-19 pandemic: a cross-sectional online survey. Inquiry 57:46958020963711. doi: $10.1177 / 0046958020963711$

da Silva, F. C. T., and Neto, M. L. R. (2020). Psychiatric symptomatology associated with depression, anxiety, distress, and insomnia in health professionals working in patients affected by COVID-19: a systematic review with meta-analysis. Prog. Neuropsychopharmacol. Biol. Psychiatry 104:110057. doi: 10.1016/j.pnpbp. 2020.110057

Dantzer, R., Cohen, S., Russo, S. J., and Dinan, T. G. (2018). Resilience and immunity. Brain Behav. Immun. 74, 28-42. doi: 10.1016/j.bbi.2018.08.010

Daskalakis, N. P., Bagot, R. C., Parker, K. J., Vinkers, C. H., and de Kloet, E. R. (2013). The three-hit concept of vulnerability and resilience: toward understanding adaptation to early-life adversity outcome. Psychoneuroendocrinology 38, 1858-1873. doi: 10.1016/j.psyneuen.2013.06.008

Davidson, J., Watkins, L., Owens, M., Krulewicz, S., Connor, K., Carpenter, D., et al. (2005). Effects of paroxetine and venlafaxine XR on heart rate variability in depression. J. Clin. Psychopharmacol. 25, 480-484. doi: 10.1097/01. jcp.0000177547.28961.03

Derijk, R. H., and de Kloet, E. R. (2008). Corticosteroid receptor polymorphisms: determinants of vulnerability and resilience. Eur. J. Pharmacol. 583, 303-311. doi: 10.1016/j.ejphar.2007.11.072

Dobson, H., Malpas, C. B., Burrell, A. J. C., Gurvich, C., Chen, L., Kulkarni, J., et al. (2020). Burnout and psychological distress amongst Australian healthcare workers during the COVID-19 pandemic. Australas. Psychiatry 29, 26-30. doi: $10.1177 / 1039856220965045$

Domes, G., Ower, N., von Dawans, B., Spengler, F. B., Dziobek, I., Bohus, M., et al. (2019). Effects of intranasal oxytocin administration on empathy and approach motivation in women with borderline personality disorder: a randomized controlled trial. Transl. Psychiatry 9:328. doi: 10.1038/s41398019-0658-4

Eddy, P., Wertheim, E. H., Hale, M. W., and Wright, B. J. (2018). A systematic review and meta-analysis of the effort-reward imbalance model of workplace stress and hypothalamic-pituitary-adrenal axis measures of stress. Psychosom. Med. 80, 103-113. doi: 10.1097/PSY.0000000000000505

Elder, G. J., Alfonso-Miller, P., Atkinson, W. C. M., Santhi, N., and Ellis, J. G. (2020). Testing an early online intervention for the treatment of disturbed sleep during the COVID-19 pandemic (sleep COVID-19): structured summary of a study protocol for a randomised controlled trial. Trials 21:704. doi: 10.1186/s13063-020-04644-0 
Elisei, S., Sciarma, T., Verdolini, N., and Anastasi, S. (2013). Resilience and depressive disorders. Psychiatr. Danub. 25(Suppl. 2), S263-S267.

Eraly, S. A., Nievergelt, C. M., Maihofer, A. X., Barkauskas, D. A., Biswas, N., Agorastos, A., et al. (2014). Assessment of plasma C-reactive protein as a biomarker of posttraumatic stress disorder risk. JAMA Psychiatry 71, 423-431. doi: 10.1001/jamapsychiatry.2013.4374

Farzi, A., Reichmann, F., and Holzer, P. (2015). The homeostatic role of neuropeptide $\mathrm{Y}$ in immune function and its impact on mood and behavior. Acta Physiol. 213, 603-627. doi: 10.1111/apha.12445

Feder, A., Fred-Torres, S., Southwick, S. M., and Charney, D. S. (2019). The biology of human resilience: opportunities for enhancing resilience across the life span. Biol. Psychiatry 86, 443-453. doi: 10.1016/j.biopsych.2019.07.012

Feldman, R. (2018). What is resilience: an affiliative neuroscience approach. World Psychiatry 19, 132-150. doi: 10.1002/wps.20729

Finegood, E. D., Rarick, J. R. D., and Blair, C.Family Life Project Investigators (2017). Exploring longitudinal associations between neighborhood disadvantage and cortisol levels in early childhood. Dev. Psychopathol. 29, 1649-1662. doi: 10.1017/S0954579417001304

Flanagan, J. C., Sippel, L. M., Santa Maria, M. M. M., Hartwell, K. J., Brady, K. T., and Joseph, J. E. (2019). Impact of oxytocin on the neural correlates of fearful face processing in PTSD related to childhood trauma. Eur. J. Psychotraumatol. 10:1606626. doi: 10.1080/20008198.2019.1606626

Fleshner, M., Maier, S. F., Lyons, D. M., and Raskind, M. A. (2011). The neurobiology of the stress-resistant brain. Stress 14, 498-502. doi: 10.3109/10253890.2011.596865

Freeman, M. P. (2020). COVID-19 from a psychiatry perspective: meeting the challenges. J. Clin. Psychiatry 81:20ed13358. doi: 10.4088/JCP.20ed13358

Frodl, T., and O'Keane, V. (2013). How does the brain deal with cumulative stress? A review with focus on developmental stress, HPA axis function and hippocampal structure in humans. Neurobiol. Dis. 52, 24-37. doi: 10.1016/j. nbd.2012.03.012

Gan, Y., Chen, Y., Han, X., Yu, N. X., and Wang, L. (2019). Neuropeptide Y gene $\times$ environment interaction predicts resilience and positive future focus. Appl. Psychol. Health Well-Being 11, 438-458. doi: 10.1111/aphw.12162

Gloster, A. T., Gerlach, A. J., Hamm, A., Hofler, M., Alpers, G. W., Kircher, T., et al. (2015). 5HTT is associated with the phenotype psychological flexibility: results from a randomized clinical trial. Eur. Arch. Psychiatry Clin. Neurosci. 265, 399-406. doi: 10.1007/s00406-015-0575-3

Gloster, A. T., Klotsche, J., Aggeler, T., Geisser, N., Juillerat, G., Schmidlin, N., et al. (2019). Psychoneuroendocrine evaluation of an acceptance and commitment based stress management training. Psychother. Res. 29, 503-513. doi: $10.1080 / 10503307.2017 .1380862$

Gonzalez-Giraldo, Y., and Forero, D. A. (2020). Association between resilience and a functional polymorphism in the serotonin transporter (SLC6A4) gene: a meta-analysis. EXCLI J. 19, 1174-1183. doi: 10.17179/excli2020-2660

Gottschalk, M. G., Domschke, K., and Schiele, M. A. (2020). Epigenetics underlying susceptibility and resilience relating to daily life stress, work stress, and socioeconomic status. Front. Psychol. 11:163. doi: 10.3389/fpsyt.2020.00163

Guevara, J. E., and Murdock, K. W. (2020). Executive functioning and rumination as they relate to stress-induced cortisol curves. J. Behav. Med. 43, 829-838. doi: 10.1007/s10865-019-00119-z

Gururajan, A., van de Wouw, M., Boehme, M., Becker, T., O'Connor, R., Bastiaanssen, T. F. S., et al. (2019). Resilience to chronic stress is associated with specific neurobiological, neuroendocrine and immune responses. Brain Behav. Immun. 80, 583-594. doi: 10.1016/j.bbi.2019.05.004

Han, Q. Q., Yang, L., Huang, H. J., Wang, Y. L., Yu, R., Wang, J., et al. (2017). Differential GR expression and translocation in the hippocampus mediates susceptibility vs. resilience to chronic social defeat stress. Front. Neurosci. 11:287. doi: 10.3389/fnins.2017.00287

Hanson, J. L., Albert, W. D., Skinner, A. T., Shen, S. H., Dodge, K. A., and Lansford, J. E. (2019). Resting state coupling between the amygdala and ventromedial prefrontal cortex is related to household income in childhood and indexes future psychological vulnerability to stress. Dev. Psychopathol. 31, 1053-1066. doi: 10.1017/S0954579419000592

Harper, K. M., Knapp, D. J., Criswell, H. E., and Breese, G. R. (2018). Vasopressin and alcohol: a multifaceted relationship. Psychopharmacology 235, 3363-3379. doi: 10.1007/s00213-018-5099-x

Haubrich, J., Bernabo, M., and Nader, K. (2020). Noradrenergic projections from the locus coeruleus to the amygdala constrain fear memory reconsolidation. elife 9:e57010. doi: 10.7554/eLife.57010
Heckenberg, R. A., Eddy, P., Kent, S., and Wright, B. J. (2018). Do workplacebased mindfulness meditation programs improve physiological indices of stress? A systematic review and meta-analysis. J. Psychosom. Res. 114, 62-71. doi: 10.1016/j.jpsychores.2018.09.010

Highland, K. B., Costanzo, M., Jovanovic, T., Norrholm, S. D., Ndiongue, R., Reinhardt, B., et al. (2015). Biomarkers of post-deployment resilience among military service members. Neurobiol. Stress 2, 62-66. doi: 10.1016/j.ynstr.2015.07.001

Highland, J. N., Zanos, P., Georgiou, P., and Gould, T. D. (2019). Group II metabotropic glutamate receptor blockade promotes stress resilience in mice. Neuropsychopharmacology 44, 1788-1796. doi: 10.1038/s41386-019-0380-1

Hodes, G. E., Pfau, M. L., Leboeuf, M., Golden, S. A., Christoffel, D. J., Bregman, D., et al. (2014). Individual differences in the peripheral immune system promote resilience versus susceptibility to social stress. Proc. Natl. Acad. Sci. U. S. A. 111, 16136-16141. doi: 10.1073/pnas.1415191111

Hokfelt, T., Barde, S., Xu, X. Q. D., Kuteeva, E., Ruegg, J., Le Maitre, E., et al. (2018). Neuropeptide and small transmitter coexistence: fundamental studies and relevance to mental illness. Front. Neural Circuits 12:106. doi: 10.3389/ fncir.2018.00106

Holmes, P. V. (2014). Trophic mechanisms for exercise-induced stress resilience: potential role of interactions between BDNF and galanin. Front. Psychiatry 5:90. doi: 10.3389/fpsyt.2014.00090

Holzer, P., Reichmann, F., and Farzi, A. (2012). Neuropeptide Y, peptide YY and pancreatic polypeptide in the gut-brain axis. Neuropeptides 46, 261-274. doi: 10.1016/j.npep.2012.08.005

Huang, Y., and Zhao, N. (2020). Generalized anxiety disorder, depressive symptoms and sleep quality during COVID-19 outbreak in China: a webbased cross-sectional survey. Psychiatry Res. 288, 1-6. doi: 10.1016/j. psychres.2020.112954

Huffmann, E. M., Athanasiadis, D. I., Anton, N. E., Haskett, L. A., Doster, D. L., Stefanidis, D., et al. (2020). How resilient is your team? Exploring healthcare providers' well-being during the COVID-19 pandemic. Am. J. Surg. doi: 10.1016/j.amjsurg.2020.09.005 [Epub ahead of print]

Hurlemann, R. (2017). Oxytocin-augmented psychotherapy: beware of context. Neuropsychopharmacology 42:377. doi: 10.1038/npp.2016.188

Huzard, D., Mumby, D. G., Carmen, S., Poirier, G. L., and van der Kooij, M. A. (2015). The effects of extrinsic stress on somatic markers and behavior are dependent on animal housing conditions. Physiol. Behav. 151, 238-245. doi: 10.1016/j.physbeh.2015.07.018

Imai, R., Hori, H., Itoh, M., Lin, M., Niwa, M., Ino, K., et al. (2019). Relationships of blood proinflammatory markers with psychological resilience and quality of life in civilian women with posttraumatic stress disorder. Sci. Rep. 9:17905. doi: 10.1038/s41598-019-54508-0

Imamura, Y., Mizoguchi, Y., Nabeta, H., Haraguchi, Y., Matsushima, J., Kojima, N., et al. (2017). An association between belief in life after death and serum oxytocin in older people in rural Japan. Int. J. Geriatr. Psychiatry 32, 102-109. doi: 10.1002/gps.4453

Ioannidis, K., Askelund, A. D., Kievit, R. A., and van Harmelen, A. L. (2020). The complex neurobiology of resilient functioning after childhood maltreatment. BMC Med. 18:32. doi: 10.1186/s12916-020-1490-7

Isingrini, E., Perret, L., Rainer, Q., Amilhon, B., Guma, E., Tanti, A., et al. (2016). Resilience to chronic stress is mediated by noradrenergic regulation of dopamine neurons. Nat. Neurosci. 19, 560-563. doi: 10.1038/nn.4245

Issler, O., Haramati, S., Paul, E. D., Maeno, H., Navon, I., Zwang, R., et al. (2014). MicroRNA 135 is essential for chronic stress resiliency, antidepressant efficacy, and intact serotonergic activity. Neuron 83, 344-360. doi: 10.1016/j. neuron.2014.05.042

Jabbi, M., Kema, I. P., van der Pompe, G., te Meerman, G. J., Ormel, J., and den Boer, J. A. (2007). Catechol-O-methyltransferase polymorphism and susceptibility to major depressive disorder modulates psychological stress response. Psychiatr. Genet. 17, 183-193. doi: 10.1097/YPG.0b013 e32808374df

Junqueira-Kipnis, A. P., Dos Anjos, L. R. B., Barbosa, L. C. S., da Costa, A. C., Borges, K. C. M., Cardoso, A. D. R. O., et al. (2020). BCG revaccination of health workers in Brazil to improve innate immune responses against COVID-19: a structured summary of a study protocol for a randomised controlled trial. Trials 21:881. doi: 10.1186/s13063-020-04822-0

Kakiashvili, T., Leszek, J., and Rutkowski, K. (2013). The medical perspective on burnout. Int. J. Occup. Med. Environ. Health 26, 401-412. doi: 10.2478/ s13382-013-0093-3 
Kaliman, P. (2019). Epigenetics and meditation. Curr. Opin. Psychol. 28, 76-80. doi: 10.1016/j.copsyc.2018.11.010

Katz, B. A., Breznitz, H., and Yovel, I. (2019). Gain through pain: augmenting in vivo exposure with enhanced attention to internal experience leads to increased resilience to distress. Behav. Res. Ther. 113, 9-17. doi: 10.1016/j. brat.2018.12.001

Ke, Y., Zhu, H., Huang, Y., Cheng, L., Wu, X., and Chen, N. (2020). Correlation between monoamine neurotransmitter and cytokine levels and the occurrence of post-traumatic stress disorder among operating room nurses. Ann. Palliat. Med. 9, 3947-3956. doi: 10.21037/apm-20-1829

Kemp, A. H., and Quintana, D. S. (2013). The relationship between mental and physical health: insights from the study of heart rate variability. Int. J. Psychophysiol. 89, 288-296. doi: 10.1016/j.ijpsycho.2013.06.018

Kinlein, S. A., and Karatsoreos, I. N. (2020). The hypothalamic-pituitary-adrenal axis as a substrate for stress resilience: interactions with the circadian clock. Front. Neuroendocrinol. 56:100819. doi: 10.1016/j.yfrne.2019.100819

Koch, S. B. J., van Zuiden, M., Nawjin, L., Frijling, J. L., Veltman, D. J., and Olff, M. (2014). Intranasal oxytocin as strategy for medication-enhanced psychotherapy of PTSD: salience processing and fear inhibition processes. Psychoneuroendocrinology 40, 242-256. doi: 10.1016/j.psyneuen.2013.11.018

Krystal, J. H., and Neumeister, A. (2009). Noradrenergic and serotonergic mechanisms in the neurobiology of posttraumatic stress disorder and resilience. Brain Res. 1293, 13-23. doi: 10.1016/j.brainres.2009.03.044

Kumsta, R. (2019). The role of epigenetics for understanding mental health difficulties and its implications for psychotherapy research. Psychol. Psychother. 92, 190-207. doi: 10.1111/papt.12227

Kunzler, A. M., Helmreich, I., Chmitorz, A., Konig, J., Binder, H., Wessa, M., et al. (2020). Psychological interventions to foster resilience in healthcare professionals. Cochrane Database Syst. Rev. 7:CD012527. doi: 10.1002/14651858. CD012527.pub2

Lacey, T., Sweeting, J., Kingston, R., Smith, M., and Markham, C. M. (2019). Neuropeptide Y impairs the acquisition of conditioned defeat in Syrian hamsters. Neurosci. Lett. 690, 214-218. doi: 10.1016/j.neulet.2018.09.049

Landi, G., Pakenham, K. I., Boccolini, G., Grandi, S., and Tossani, E. (2020). Health anxiety and mental health outcome during COVID-19 lockdown in Italy: the mediating and moderating roles of psychological flexibility. Front. Psychol. 11:2195. doi: 10.3389/fpsyg.2020.02195

Larson, N., Slaughter-Acey, J., Alexander, T., Berge, J., Harnack, L., and Neumarck-Sztainer, D. (2020). Emerging adults' intersecting experiences of food insecurity, unsafe neighbourhoods, and discrimination during the COVID-19 outbreak. Public Health Nutr. 24, 519-530. doi: 10.1017/S136898002000422X

Lee, S. M., Kang, W. S., Cho, A., Kim, T., and Park, J. K. (2018). Psychological impact of the 2015 MERS outbreak on hospital workers and quarantined hemodialysis patients. Compr. Psychiatry 87, 123-127. doi: 10.1016/j. comppsych.2018.10.033

Lenze, E. J., Mattar, C., Zorumski, C. F., Stevens, A., Schweiger, J., Nicol, G. E., et al. (2020). Fluvoxamine vs. placebo and clinical deterioration in outpatients with symptomatic COVID-19: a randomized controlled trial. JAMA 324, 2292-2300. doi: 10.1001/jama.2020.22760

Levone, B. R., Cryan, J. F., and O'Leary, O. F. (2015). Role of adult hippocampal neurogenesis in stress resilience. Neurobiol. Stress 1, 147-155. doi: 10.1016/j. ynstr.2014.11.003

Lewis, G. F., Hourani, L., Tueller, S., Kizakevich, P., Bryant, S., Weimer, B., et al. (2015). Relaxation training assisted by heart rate variability biofeedback: implication for a military predeployment stress inoculation protocol. Psychophysiology 52, 1167-1174. doi: 10.1111/psyp.12455

Lewitus, G. M., Cohen, H., and Schwartz, M. (2008). Reducing post-traumatic anxiety by immunization. Brain Behav. Immun. 22, 1108-1114. doi: 10.1016/j. bbi.2008.05.002

Li, W. X. (2021). Worldwise inverse correlation between Bacille Calmette-Guerin (BCG) immunization and COVID-19 mortality. Infection 1-11. doi: 10.1007/ s15010-020-01566-6

Li, Z., Ge, J., Yang, M., Feng, J., Qiao, M., Jiang, R., et al. (2020). Vicarious traumatization in the general public, members, and non-members of medical teams aiding in COVID-19 control. Brain Behav. Immun. 88, 916-919. doi: 10.1016/j.bbi.2020.03.007

Li, Y., Hassett, A. L., and Seng, J. S. (2019). Exploring the mutual regulation between oxytocin and cortisol as a marker of resilience. Arch. Psychiatr. Nurs. 33, 164-173. doi: 10.1016/j.apnu.2018.11.008
Llinas, R. H., Marsh, E. B., and Gamaldo, C. E. (2018). Residency training: enhancing resiliency in our residents: combining the principles of business and neurobiology. Neurology 91, e1721-e1723. doi: 10.1212/WNL.0000000000006431

Loupy, K. M., Cler, K. E., Marquart, B. M., Yifru, T. W., D’Angelo, H. M., Arnold, M. R., et al. (2021). Comparing the effects of two different strains of mycobacteria, Mycobacterium vaccae NCTC 11659 and M. vaccae ATCC 15483 , on stress-resilient behaviors and lipid-immune signalling in rats. Brain Behav. Immun. 91, 212-229. doi: 10.1016/j.bbi.2020.09.030

Madsen, A. M. R., Schaltz-Buchholzer, F., Benfield, T., Bjerregaard-Andersen, M., Dalgaard, L. S., Dam, C., et al. (2020). Using BCG vaccine to enhance non-specific protection of health care workers during the COVID-19 pandemic: a structured summary of a study protocol for a randomized controlled trial in Denmark. Trials 21:799. doi: 10.1186/s13063-020-04714-3

Maehata, H., Kobayashi, Y., Mistuyama, E., Kawase, T., Kuhara, T., Xiao, J. Z., et al. (2019). Heat-killed lactobacillus helveticus strain MCC1848 confers resilience to anxiety or depression-like symptoms caused by subchronic social defeat stress in mice. Biosci. Biotechnol. Biochem. 83, 1239-1247. doi: $10.1080 / 09168451.2019 .1591263$

Maunder, R. G., Leszcz, M., Savage, D., Adam, M. A., Peladeau, N., Romano, D., et al. (2008). Applying the lessons of SARS to pandemic influenza: an evidence-based approach to mitigating the stress experienced by healthcare workers. Can. J. Public Health 99, 486-488. doi: 10.1007/BF03403782

McGhee, L. L., Maani, C. V., Garza, T. H., Gaylord, K. M., and Black, I. H. (2008). The correlation between ketamine and posttraumatic stress disorder in burned service members. J. Trauma 64, S195-S198. doi: 10.1097/ TA.0b013e318160bald

Meyer-Lindenberg, A., Domes, G., Kirsch, P., and Heinrichs, M. (2011). Oxytocin and vasopressin in the human brain: social neuropeptides for translational medicine. Nat. Rev. Neurosci. 12, 524-538. doi: 10.1038/nrn3044

Michopoulos, V., Beurel, E., Gould, F., Dhabhar, F. S., Schultebraucks, K., Galatzer-Levy, I., et al. (2020). Association of prospective risk for chronic PTSD symptoms with low TNF $\alpha$ and IFN $\gamma$ concentrations in the immediate aftermath of trauma exposure. Am. J. Psychiatry 177, 58-65. doi: 10.1176/ appi.ajp.2019.19010039

Miller, G. E., Yu, T., Chen, E., and Brody, G. E. (2015). Self-control forecasts better psychosocial outcomes but faster epigenetic aging in low-SES youth Proc. Natl. Acad. Sci. U. S. A. 112, 10325-10330. doi: 10.1073/pnas.1505063112

Muhie, S., Gautam, A., Chakraborty, N., Hoke, A., Meyerhoff, J., Hammamieh, R., et al. (2017). Molecular indicators of stress-induced neuroinflammation in a mouse model simulating features of post-traumatic stress disorder. Transl. Psychiatry 7:e1135. doi: 10.1038/tp.2017.91

Muller, A. E., Hafstad, E. V., Himmels, J. P. W., Smedslund, G., Flottorp, S., Stensland, S. O., et al. (2020). The mental health impact of the COVID-19 pandemic on healthcare workers, and interventions to help them: a rapid systematic review. Psychiatry Res. 293:113441. doi: 10.1016/j.psychres.2020.113441

Muñoz-Cobo, I., Erburu, M. M., Zwergel, C., Cirilli, R., Mai, A., Valente, S., et al. (2018). Nucleocytoplasmic export of HDAC5 and SIRT2 downregulation: two epigenetic mechanisms by which antidepressants enhance synaptic plasticity markers. Psychopharmacology 235, 2831-2846. doi: 10.1007/ s00213-018-4975-8

Nam, H., Chandra, R., Francis, T. C., Dias, C., Cheer, J. F., and Lobo, M. K. (2019). Reduced nucleus accumbens enkephalins underlie vulnerability to social defeat stress. Neuropsychopharmacology 44, 1876-1885. doi: 10.1038/ s41386-019-0422-8

Narendran, R., Tollefson, S., Fasenmeyer, K., Paris, J., Himes, M. L., Lopresti, B., et al. (2019). Decreased nociception receptors are related to resilience and recovery in college women who have experienced sexual violence: therapeutic implications for PTSD. Biol. Psychiatry 85, 1056-1064. doi: 10.1016/j. biopsych.2019.02.017

Nasca, C., Menard, C., Hodes, G., Bigio, B., Pena, C., Lorsch, Z., et al. (2019). Multidimensional predictors of susceptibility and resilience to social defeat stress. Biol. Psychiatry 86, 483-491. doi: 10.1016/j.biopsych.2019.06.030

Nieto-Gonzalez, J. L., Holm, M. M., Vardya, I., Christensen, T., Wiborg, O., and Jensen, K. (2015). Presynaptic plasticity as a hallmark of rat stress susceptibility and antidepressant response. PLoS One 10:e0119993. doi: 10.1371/journal.pone.0119993

Nivethitha, L., Mooventhan, A., and Manjunath, N. K. (2016). Effect of various pranayama on cardiovascular and autonomic variables. Anc. Sci. Life 36 72-77. doi: 10.4103/asl.ASL_178_16 
Notaras, M., and van den Buuse, M. (2020). Neurobiology of BDNF in fear memory, sensitivity to stress, and stress-related disorders. Mol. Psychiatry 25, 2251-2274. doi: 10.1038/s41380-019-0639-2

Nowicki, G. J., Slusarska, B., Tucholska, K., Naylor, K., Chrzan-Rodak, A., and Niedorys, B. (2020). The severity of traumatic stress associated with COVID-19 pandemic, perception of support, sense of security, and sense of meaning in life among nurses: research protocol and preliminary results from Poland. Int. J. Environ. Res. Public Health 17:E6491. doi: 10.3390/ijerph17186491

Olff, M., Amstadter, A., Armour, C., Birkeland, M. S., Bui, E., Cloitre, M., et al. (2019). A decennial review of psychotraumatology: what did we learn and where are we going? Eur. J. Psychotraumatol. 10:1672948. doi: 10.1080/ 20008198.2019.1672948

Onigbinde, O. A., Babatunde, O., and Ajagbe, A. O. (2020). The welfare of healthcare workers amidst COVID-19 pandemic in sub-Sahara Africa: a call for concern. Ethics, Med. Public Health 15:100555. doi: 10.1016/j.jemep.2020.100555

Page, G. G., Opp, M. R., and Kozachik, S. L. (2014). Reduced sleep, stress responsivity, and female sex contribute to persistent inflammation-induced mechanical hypersensitivity in rats. Brain Behav. Immun. 40, 244-251. doi: 10.1016/j.bbi.2014.02.013

Pan-Vazquez, A., Rye, N., Ameri, M., McSparron, B., Smallwood, G., Bickerdyke, J., et al. (2015). Impact of voluntary exercise and housing conditions on hippocampal glucocorticoid receprot, miR-124 and anxiety. Mol. Brain 8:40. doi: 10.1186/s13041-015-0128-8

Pape, J. C., Carrillo-Roa, T., Rothbaum, B. O., Nemeroff, C. B., Czamara, D., Zannas, A. S., et al. (2018). DNA methylation levels are associated with CRF1 receptor antagonist treatment outcome in women with post-traumatic stress disorder. Clin. Epigenetics 10:136. doi: 10.1186/s13148-018-0569-x

Pappa, S., Ntella, V., Giannakas, T., Giannakoulis, V. G., Papoutsi, E., and Katsaounou, P. (2020). Prevalence of depression, anxiety, and insomnia among healthcare workers during the COVID-19 pandemic: a systematic review and meta-analysis. Brain Behav. Immun. 88, 901-907. doi: 10.1016/j. bbi.2020.05.026

Perry, R. E., Rincon-Cortes, M., Braren, S. H., Brandes-Aitken, A. N., Opendak, M., Polloninin, G., et al. (2019). Corticosterone administration targeting a hyporeactive HPA axis rescues a socially-avoidant phenotype in scarcity-adversity reared rats. Dev. Cogn. Neurosci. 40:100716. doi: 10.1016/j.dcn.2019.100716

Pertille, F., Ibelli, A. M. G., El Sharif, M., Poleti, M. D., Frohlich, A. S., Rezaei, S., et al. (2020). Putative epigenetic biomarkers of stress in red blood cells of chickens reared across different biomes. Front. Genet. 11:508809. doi: 10.3389/fgene.2020.508809

Plessow, F., Eddy, K. T., and Lawson, E. A. (2018). The neuropeptide hormone oxytocin in eating disorders. Curr. Psychiatry Rep. 20:91. doi: 10.1007/ s11920-018-0957-0

Prakash, N., Stark, C. J., Keisler, M. N., Luo, L., Der-Avakian, A., and Dulcis, D. (2020). Serotonergic plasticity in the dorsal raphe nucleus characterizes susceptibility and resilience to anhedonia. J. Neurosci. 40, 569-584. doi: 10.1523/JNEUROSCI.1802-19.2019

Radmark, L., Sidorchuk, A., Osika, W., and Niemi, M. (2019). A systematic review and meta-analysis of the impact of mindfulness based interventions on heart rate variability and inflammatory markers. J. Clin. Med. 8:1638. doi: $10.3390 / \mathrm{jcm} 8101638$

Rajkumar, R. P. (2020). Sleep, physical activity and mental health during the COVID-19 pandemic: complexities and opportunities for intervention. Sleep Med. 77, 307-308. doi: 10.1016/j.sleep.2020.10.004

Rakesh, G., Morey, R. A., Zannas, A. S., Malik, Z., Marx, C. E., Clausen, A. N., et al. (2019). Resilience as a translational endpoint in the treatment of PTSD. Mol. Psychiatry 24, 1268-1283. doi: 10.1038/s41380-019-0383-7

Reber, S. O., Siebler, P. H., Donner, N. C., Morton, J. T., Smith, D. G., Kopelman, J. M., et al. (2016). Immunization with a heat-killed preparation of the environmental bacterium Mycobacterium vaccae promotes stress resilience in mice. Proc. Natl. Acad. Sci. U. S. A. 113, E3130-E3139. doi: 10.1073/pnas. 1600324113

Reichmann, F., and Holzer, P. (2016). Neuropeptide Y: a stressful review. Neuropeptides 55, 99-109. doi: 10.1016/j.npep.2015.09.008

Reul, J. M. H. M., Collins, A., Saliba, R. S., Mifsud, K. R., Carter, S. D., Gutierrez-Mecinas, M., et al. (2014). Glucocorticoids, epigenetic control and stress resilience. Neurobiol. Stress 1, 44-59. doi: 10.1016/j.ynstr.2014.10.001

Richter-Levin, G., and Xu, L. (2018). How could stress lead to major depressive disorder? IBRO Rep. 4, 38-43. doi: 10.1016/j.ibror.2018.04.001
Roberts, S., Keers, R., Lester, K. J., Coleman, J. R. I., Breen, G., Arendt, K., et al. (2015). HPA axis related genes and response to psychological therapies: genetics and epigenetics. Depress. Anxiety 32, 861-870. doi: 10.1002/da.22430

Rosen, B., Preisman, M., Hunter, J., and Maunder, R. G. (2020). Applying psychotherapeutic principles to bolster resilience among health care workers during the COVID-19 pandemic. Am. J. Psychother. 73, 144-148. doi: 10.1176/ appi.psychotherapy.20200020

Rutter, M. (2012). Resilience as a dynamic concept. Dev. Psychopathol. 24, 335-344. doi: 10.1017/S0954579412000028

Sah, R., Ekhator, N. N., Jefferson-Wilson, L., Horn, P. S., and Geracioti, T. D. (2014). Cerebrospinal fluid neuropeptide $\mathrm{Y}$ in combat veterans with and without posttraumatic stress disorder. Psychoneuroendocrinology 40, 277-283. doi: 10.1016/j.psyneuen.2013.10.017

Salari, N., Khazaie, H., Hosseinian-Far, A., Ghasemi, H., Mohammadi, M., Shohaimi, S., et al. (2020). The prevalence of sleep disturbances among physicians and nurses facing the COVID-19 patients: a systematic review and meta-analysis. Glob. Health 16:92. doi: 10.1186/s12992-020-00620-0

Saletin, J. M., Goldstein-Piekarski, A. N., Greer, S. M., Stark, S., Stark, C. E., and Walker, M. P. (2016). Human hippocampal structure: a novel biomarker predicting mnemonic vulnerability to, and recovery from, sleep deprivation. J. Neurosci. 36, 2355-2363. doi: 10.1523/JNEUROSCI.3466-15.2016

Sciolino, N. R., Smith, J. M., Stranahan, A. M., Freeman, K. G., Edwards, G. L., Weinshenker, D., et al. (2015). Galanin mediates features of neural and behavioral stress resilience afforded by exercise. Neuropharmacology 89, 255-264. doi: 10.1016/j.neuropharm.2014.09.029

Shariq, A. S., Rosenblat, J. D., Alageel, A., Mansur, R. B., Rong, C., Ho, R. C., et al. (2019). Evaluating the role of orexins in the pathophysiology and treatment of depression: a comprehensive review. Prog. Neuro-Psychopharmacol. Biol. Psychiatry 92, 1-7. doi: 10.1016/j.pnpbp.2018.12.008

Sharma, S. R., Gonda, X., Dome, P., and Tarazi, F. I. (2020). What's love got to do with it: role of oxytocin in trauma, attachment and resilience. Pharmacol. Ther. 214:107602. doi: 10.1016/j.pharmthera.2020.107602

Shields, A. E., Wise, L. A., Ruiz-Narvaez, E. A., Seddighzadeh, B., Byun, H. -M., Cozier, Y. C., et al. (2016). Childhood abuse, promoter methylation of leukocyte $\mathrm{NR} 3 \mathrm{C} 1$ and the potential modifying effect of emotional support. Epigenomics 8, 1507-1517. doi: 10.2217/epi-2016-0074

Simpson, R. J., and Katsanis, E. (2020). The immunological case for staying active during the COVID-19 pandemic. Brain Behav. Immun. 87, 6-7. doi: 10.1016/j.bbi.2020.04.041

Sipahi, L., Uddin, M., Hou, Z. -C., Aiello, A. E., Koenen, K. C., Galea, S., et al. (2014). Ancient evolutionary origins of epigenetic regulation associated with posttraumatic stress disorder. Front. Hum. Neurosci. 8:284. doi: 10.3389/ fnhum.2014.00284

Sippel, L. A., Han, S., Watkins, L. E., Harpaz-Rotem, I., Southwick, S. M., Krystal, J. H., et al. (2017). Oxytocin receptor gene polymorphisms, attachment and PTSD: results from the National Health and resilience in veterans study. J. Psychiatr. Res. 94, 139-147. doi: 10.1016/j.jpsychires. 2017.07.008

Smith, B. M., Twohy, A. J., and Smith, G. S. (2020). Psychological inflexibility and intolerance of uncertainty moderate the relationship between social isolation and mental health outcomes during COVID-19. J. Contextual Behav. Sci. 18, 162-174. doi: 10.1016/j.jcbs.2020.09.005

Sotgiu, G., and Dobler, C. C. (2020). Social stigma in the time of coronavirus. Eur. Respir. J. 56:2002461. doi: 10.1183/13993003.02461-2020

Spierling, S. R., and Zorrilla, E. P. (2017). Don't stress about CRF: assessing the translational failures of CRF1 antagonists. Psychopharmacology 234, 1467-1481. doi: 10.1007/s00213-017-4556-2

Staton, C. D., Yaeger, J. D. W., Khalid, D., Haroun, F., Fernandez, B. S., Fernandez, J. S., et al. (2018). Orexin 2 receptor stimulation enhances resilience, while orexin 2 inhibition promotes susceptibility, to social stress, anxiety and depression. Neuropharmacology 143, 79-94. doi: 10.1016/j. neuropharm.2018.09.016

Stein, M. B., Choi, K. W., Jain, S., Campbell-Sills, L., Chen, C. Y., Gelernter, J. et al. (2019). Genome-wide analyses of psychological resilience in U.S. Army soldiers. Am. J. Med. Genet. B Neuropsychiatr. Genet. 180B, 310-319. doi: 10.1002/ajmg.b.32730

Stengel, A., and Tache, Y. F. (2017). Activation of brain somatostatin signaling suppresses CRF receptor-mediated stress response. Front. Neurosci. 11:231. doi: $10.3389 /$ fnins.2017.00231 
Strekalova, T., Svirin, E., Waider, J., Gorlova, A., Cespuglio, R., Kalueff, A., et al. (2020). Altered behaviour, dopamine and norepinephrine regulation in stressed mice heterozygous in TPH2 gene. Prog. Neuro-Psychopharmacol. Biol. Psychiatry 110155. doi: 10.1016/j.pnpbp.2020.110155 [Epub ahead of print]

Sullivan, S., Kelli, H. M., Hammadah, M., Topel, M., Wilmot, K., Ramadan, R., et al. (2019). Neighborhood poverty and hemodynamic, neuroendocrine, and immune response to acute stress among patients with coronary artery disease. Psychoneuroendocrinology 100, 145-155. doi: 10.1016/j.psyneuen.2018.09.040

Summers, C. H., Yaeger, J. D. W., Staton, C. D., Arendt, D. H., and Summers, T. R. (2020). Orexin/hypocretin receptor modulation of anxiolytic and antidepressive responses during social stress and decision-making: potential for therapy. Brain Res. 1731:146085. doi: 10.1016/j.brainres.2018.12.036

Sweeten, B. L. W., Adkins, A. M., Wellman, L. L., and Sanford, L. D. (2021). Group II metabotropic glutamate receptor activation in the basolateral amygdala mediates individual differences in stress-induced changes in rapid eye movement sleep. Prog. Neuro-Psychopharmacol. Biol. Psychiatry 104:110014. doi: $10.1016 /$ j.pnpnp.2020.110014

Taliaz, D., Loya, A., Gersner, R., Haramati, S., Chen, A., and Zangen, A. (2011). Resilience to chronic stress is mediated by hippocampal brain-derived neurotrophic factor. J. Neurosci. 31, 4475-4483. doi: 10.1523/JNEUROSCI. 5725-10.2011

Taylor, S., Landry, C. A., Rachor, G. S., Paluszek, M. M., and Asmundson, G. J. G. (2020a). Fear and avoidance of healthcare workers: an important, underrecognized form of stigmatization during the COVID-19 pandemic. J. Anxiety Disord. 75:102289. doi: 10.1016/j.janxdis.2020.102289

Taylor, A. M., Thompson, S. V., Edwards, C. G., Musaad, S. M. A., Khan, N. A., and Holscher, H. D. (2020b). Associations among diet, the gastrointestinal microbiota, and negative emotional states in adults. Nutr. Neurosci. 23, 983-992. doi: 10.1080/1028415X.2019.1582578

Thomaes, K., de Kloet, C., Wilker, S., El-Hage, W., Schafer, I., Kleim, B., et al. (2016). Investigating biological traces of traumatic stress in changing societies: challenges and directions from the ESTSS task force on neurobiology. Eur. J. Psychotraumatol. 7:29453. doi: 10.3402/ejpt.v7.29453

Tonnesen, M. T., Miani, A., Pedersen, A. S., Mitkidis, P., Zak, P. J., and Winterdahl, M. (2018). Neuropeptide Y and religious commitment in healthy young women. Acta Neuropsychiatr. 1-7. doi: 10.1017/neu.2018.34

Tooley, K. L. (2020). Effects of the human gut microbiota on cognitive performance, brain structure and function: a narrative review. Nutrients 12:E3009. doi: $10.3390 /$ nu12103009

Toyoda, A. (2020). Nutritional interventions for promoting stress resilience: recent progress using psychosocial stress models of rodents. Anim. Sci. J. 91:e13478. doi: 10.1111/asj.13478

van Praag, H., Kempermann, G., and Gage, F. H. (2000). Neural consequences of environmental enrichment. Nat. Rev. Neurosci. 1, 191-198. doi: 10.1038/ 35044558

Vinkers, C. H., van Amelsvoort, T., Bisson, J. I., Branchi, I., Cryan, J. F., Domschke, K., et al. (2020). Stress resilience during the coronavirus pandemic. Eur. Neuropsychopharmacol. 35, 12-16. doi: 10.1016/j.euroneuro.2020.05.003

Wagner, K. V., Hartmann, J., Labermaier, C., Hausl, A. S., Zhao, G., Harbich, D., et al. (2015). HomerI/mGluR5 activity moderates vulnerability to chronic social stress. Neuropsychopharmacology 40, 1222-1233. doi: 10.1038/npp.2014.308

Wang, M., Baker, J. S., Quan, W., Shen, S., Fekete, G., and Gu, Y. (2020a). A preventive role of exercise across the coronavirus 2 (SARS-CoV-2) pandemic. Front. Physiol. 11:572718. doi: 10.3389/fphys.2020.572718

Wang, J., Hodes, G. E., Zhang, H., Zhang, S., Zhao, W., Golden, S. A., et al. (2018). Epigenetic modulation and synaptic plasticity promotes resilience against stress in mice. Nat. Commun. 9:477. doi: 10.1038/s41467-017-02794-5

Wang, F., Yang, J., Pan, F., Ho, R. C., and Huang, J. H. (2020b). Editorial: neurotransmitters and emotions. Front. Psychol. 11:21. doi: 10.3389/fpsyg. 2020.00021
Weinbroum, A. A. (2021). Perspectives of ketamine use in COVID-19 patients. J. Korean Med. Sci. 36:e28. doi: 10.3346/jkms.2021.36.e28

Westfall, S., Caracci, F., Zhao, D., Wu, Q. -L., Frolinger, T., Simon, J., et al. (2021). Microbiota metabolites modulate the $\mathrm{T}$ helper 17 to regulatory $\mathrm{T}$ cell (Th17/Treg) imbalance promoting resilience to stress-induced anxiety and depressive-like behaviors. Brain Behav. Immun. 91, 350-368. doi: 10.1016/j. bbi.2020.10.013

Winter, J., and Jurek, B. (2019). The interplay between oxytocin and the CRF system: regulation of the stress response. Cell Tissue Res. 375, 85-91. doi: 10.1007/s00441-018-2866-2

Wu, G., Feder, A., Cohen, H., Kim, J. J., Calderon, S., Charney, D. S., et al. (2013). Understanding resilience. Front. Behav. Neurosci. 7:10. doi: 10.3389/ fnbeh.2013.00010

Yang, Y. C., Schorpp, K., and Harris, K. M. (2014). Social support, social strain and inflammation: evidence from a national longitudinal study of U.S. adults. Soc. Sci. Med. 107, 124-135. doi: 10.1016/j.socscimed.2014.02.013

Yehuda, R., Spiegel, D., Southwick, S., Davis, L. L., Neylan, T. C., and Krystal, J. H. (2016). What I have changed my mind about and why. Eur. J. Psychotraumatol. 7:33768. doi: 10.3402/ejpt.v7.33768

Yovell, Y., Bar, G., Mashiah, M., Baruch, Y., Briskman, I., Asherov, J., et al. (2016). Ultra-low-dose buprenorphine as a time-limited treatment for severe suicidal ideation: a randomized controlled trial. Am. J. Psychiatry 173, 491-498. doi: 10.1176/appi.ajp.2015.15040535

Zannas, A. S., and West, A. E. (2014). Epigenetics and the regulation of stress vulnerability and resilience. Neuroscience 264, 157-170. doi: 10.1016/j. neuroscience.2013.12.003

Zhang, L., Hu, X. Z., Li, X., Benedek, D. M., Fullerton, C. S., Wynn, G., et al. (2020a). Potential chemokine biomarkers associated with PTSD onset, risk and resilience as well as stress responses in US military service members. Transl. Psychiatry 10:31. doi: 10.1038/s41398-020-0693-1

Zhang, W. R., Wang, K., Yin, L., Zhao, W. F., Xue, Q., Peng, M., et al. (2020b). Mental health and psychosocial problems of medical health workers during the COVID-19 epidemic in China. Psychother. Psychosom. 89, 242-250. doi: $10.1159 / 000507639$

Zheng, Z., Han, W., Li, Y., Wang, D., Gu, S., and Wang, F. (2020). The mediating effect of coping style in the relationship between depression and disordered eating among Chinese female undergraduates. Front. Psychol. 10:3011. doi: 10.3389/fpsyg.2019.03011

Zohar, J., Juven-Wetzler, A., Sonnino, R., Cwikel-Hamzany, S., Balaban, E., and Cohen, H. (2011). New insights into secondary prevention in post-traumatic stress disorder. Dialogues Clin. Neurosci. 13, 301-309. doi: 10.31887/ DCNS.2011.13.2/jzohar

Zorn, J. V., Schur, R. R., Boks, M. P., Kahn, R. S., Joels, M., and Vinkers, C. H. (2017). Cortisol stress reactivity across psychiatric disorders: a systematic review and meta-analysis. Psychoneuroendocrinology 77, 25-36. doi: 10.1016/j. psyneuen.2016.11.036

Zovkic, I. B., Meadows, J. P., Kaas, G. A., and Sweatt, J. D. (2013). Interindividual variability in stress susceptibility: a role for epigenetic mechanisms in PTSD. Front. Psychol. 4:60. doi: 10.3389/fpsyt.2013.00060

Conflict of Interest: The authors declare that the research was conducted in the absence of any commercial or financial relationships that could be construed as a potential conflict of interest.

Copyright $\odot 2021$ Rajkumar. This is an open-access article distributed under the terms of the Creative Commons Attribution License (CC BY). The use, distribution or reproduction in other forums is permitted, provided the original author(s) and the copyright owner(s) are credited and that the original publication in this journal is cited, in accordance with accepted academic practice. No use, distribution or reproduction is permitted which does not comply with these terms. 